\title{
A Study of Satisfaction and Perceived Learning and Development of Peer Mentors in Higher Education
}

\author{
Karen L. Posa \\ West Virginia University
}

Follow this and additional works at: https://researchrepository.wvu.edu/etd

\section{Recommended Citation}

Posa, Karen L., "A Study of Satisfaction and Perceived Learning and Development of Peer Mentors in Higher Education" (2011). Graduate Theses, Dissertations, and Problem Reports. 3065.

https://researchrepository.wvu.edu/etd/3065

This Dissertation is protected by copyright and/or related rights. It has been brought to you by the The Research Repository @ WVU with permission from the rights-holder(s). You are free to use this Dissertation in any way that is permitted by the copyright and related rights legislation that applies to your use. For other uses you must obtain permission from the rights-holder(s) directly, unless additional rights are indicated by a Creative Commons license in the record and/ or on the work itself. This Dissertation has been accepted for inclusion in WVU Graduate Theses, Dissertations, and Problem Reports collection by an authorized administrator of The Research Repository @ WVU.

For more information, please contact researchrepository@mail.wvu.edu. 
A Study of Satisfaction and Perceived Learning and Development of Peer Mentors in Higher Education

\author{
Karen L. Posa
}

Dissertation submitted to the College of Human Resources and Education

At West Virginia University In partial fulfillment of the requirements

for the degree of

Doctor of Education

in

Educational Leadership

Elizabeth A. Jones, Ph.D. Chair Ernest R. Goeres, Ph.D. Susan Aloi, Ed.D.

Gary J. Dean, Ph.D. Richard T. Walls, Ph.D.

Department of Educational Leadership

Morgantown, West Virginia

2011

Keywords: Mentoring, Peer Mentor, Learning and Development 


\begin{abstract}
A Study of Satisfaction and Perceived Learning and Development of

Peer Mentors in Higher Education
\end{abstract}

Karen L. Posa

The purpose of this study was to examine the satisfaction and perceived learning and development of university peer mentors. Mentoring research exists that focus on student retention, academic achievement, and satisfaction of university students who are mentored, but little research exists that provides a comprehensive, quantitative perspective of learning and development of university peer mentors.

This study was conducted at a master's level, public university which has an extensive peer mentoring program designed to assist new students with the transition to the university. The peer mentors are primarily traditionally-aged students (under the age of 25), and the majority of these students live on or near campus. An on-line survey, which measured satisfaction and perceived learning and development, Survey Regarding Satisfaction, Learning and Development of Peer Mentors in Higher Education, was distributed to 600 student peer mentors during the spring 2011 semester. Over 50\% $(\mathrm{N}=317)$ of peer mentors responded.

Based on the literature review, nine categories of learning and development were created: Academic Success, Collaboration, Communication Skills, Decision-Making and ProblemSolving, Diversity, Intrinsic Benefits, Leadership Involvement, Reflection and Student Engagement. This study found that peer mentors perceive that they are learning and developing in seven of the nine categories. The two categories in which peer mentors did not perceive gains are Leadership Involvement and Student Engagement. Over one-third of the peer mentors reported that they were neutral or disagreed that since becoming a peer mentor they participated in leadership development opportunities (such as leadership courses and/or workshops), held one leadership position in a student organization, participated in campus activities more often, or felt more comfortable asking questions in class.

Statistically significant differences were identified in two learning and development categories, based on years students served as mentors. Peer mentors who served two years in that role reported higher agreement that they were more involved in leadership opportunities than mentors who served one year and, they also reported higher agreement than three-or-more-year mentors that they were more engaged on campus.

Statistically significant differences were also identified in four learning and development categories, based on the college in which the peer mentors' major is housed. Liberal Arts mentors reported less agreement that their communication skills and intrinsic benefits have been enhanced in comparison to the Science and Technology peer mentors. The Liberal Arts mentors also reported less agreement that they have enhanced their reflection skills or are more engaged on campus, in comparison to both the Education and Human Service and Science and Technology peer mentors.

This study found that peer mentors are satisfied with the mentoring program staff and their mentoring experience. No significant differences were identified based on years of service as a mentor and based on the college in which their major is housed. 
This study provides comprehensive quantitative research to measure learning and development of peer mentors in a university setting. Practitioners could use this information to re-examine how peer mentors are encouraged to engage in leadership opportunities and overall student engagement, in- and out-of-the-classroom. Further examination needs to explore why Liberal Arts peer mentors reported less agreement than the Education and Human Services and Science and Technology peer mentors in regard to communication skills, intrinsic benefits, reflection, and student engagement. 
Peer Mentors' Learning and Development iv

\section{Acknowledgements}

I want to thank everyone who has been involved in guiding me through this doctoral studies journey. First, I want to thank my dissertation committee. Each of you has played an important role in providing guidance and support during my program of study. Dr. Elizabeth Jones, thank you for serving as my chair and advisor. Your patience, dedication, and expertise are truly appreciated. Dr. Ernest Goeres, your ever-so-kind words of wisdom and encouragement will always be cherished. Dr. Richard Walls, I will miss my visits to WVU and our statistical discussions. I can't thank you enough for your patience and time. Dr. Gary Dean, you have been part of my educational journey for over 10 years. I appreciate all that you have done over that time to challenge me, support me, and especially share your great sense of humor. Dr. Susan Aloi, thank you for being a great teacher. I am so happy I had the chance to have you for a number of classes.

A special thanks to all of my colleagues (and mentors) of past and present who have instilled a spirit of continuous learning and who have supported and cheered me on as I progressed through my educational journey: Dr. Angelone, Dr. Armenti, Dr. Campbell, Dr. Kennedy, Dr. Koury, Dr. Nettles, Provost Jones, Dr. Saludis, Mrs. Stirling, and Dr. West! A special thanks to Dr. McGukin for our great discussions on research and life in general. To my office mates, Monika and Dori, thank you for your patience and encouragement. Dori, I appreciate how you were always there for me, no matter what day or time, to provide feedback.

This dissertation is dedicated to my family and friends. Without all of you, I wouldn't have been able to accomplish this big task. First, I want to thank Joan, my mom. No matter what obstacles have come my way, you have always been there for me. Mike, thank you for 
your never-ending love and support. Thank you for being part of my life. To my friends, thank you for your calls, visits, and patience while I was too busy to play. 


\section{Table of Contents}

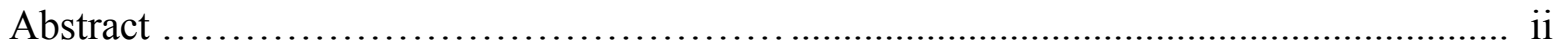

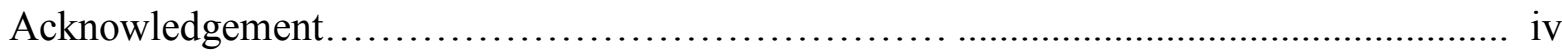

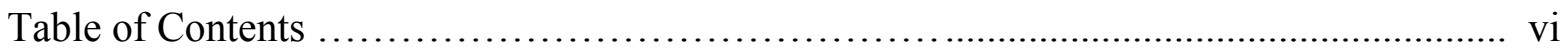

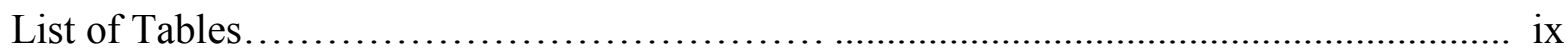

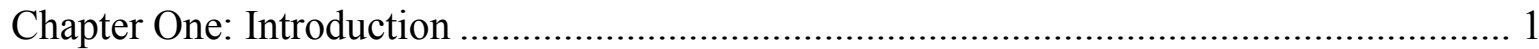

Introduction and Statement of the Problem ........................................................ 1

Purpose of this Study and Research Questions .................................................... 3

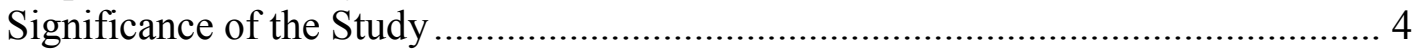

Organization of the Dissertation .................................................................... 4

Chapter Two: Review of the Literature ..................................................................... 6

Historical Perspective of Mentoring ............................................................ 6

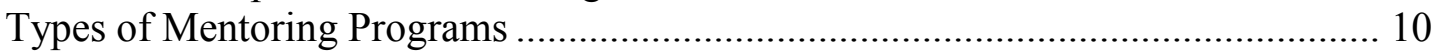

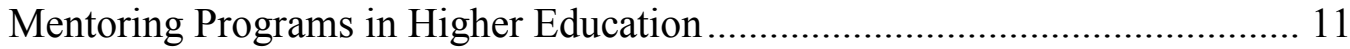

Students Serving as Peer Mentors.......................................................... 11

The Role of Peer Mentors .................................................................. 12

Selecting Peer Mentors .......................................................................... 12

Recruiting Protégés ........................................................................ 13

Matching Protégés with Peer Mentors .................................................... 14

Longevity of the Peer Mentoring Relationship......................................... 14

Student Learning and Development.................................................................... 15

Learning and Development of the Peer Mentors ......................................... 17

Student Engagement and Peer Mentors ..................................................... 20

Peer Mentors and Reflection........................................................................ 22

Intrinsic Benefits for Peer Mentors ................................................................. 23

Satisfaction and Peer Mentors ........................................................................... 23

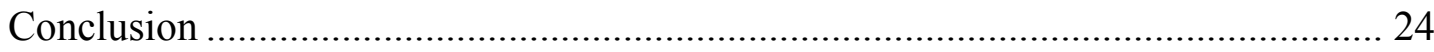

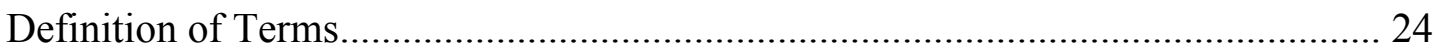

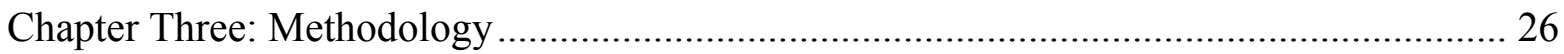

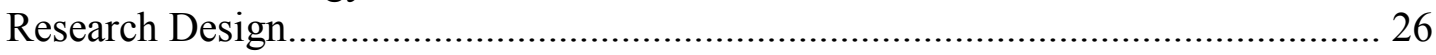

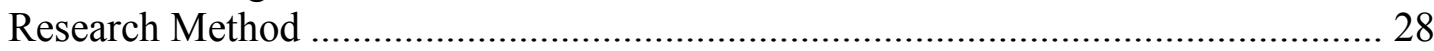

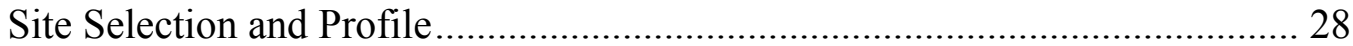

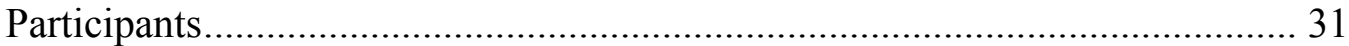

Data Collection and Survey Instrument................................................ 31

Pilot Study Results ...................................................................... 32

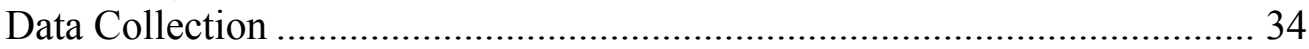

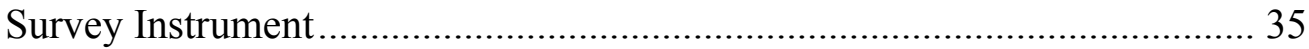




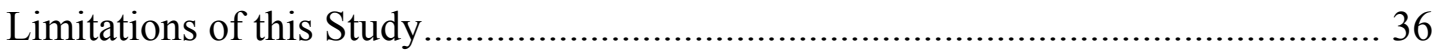

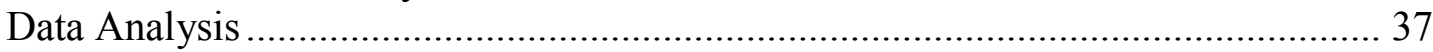

Research Questions with Corresponding Survey Items............................... 42

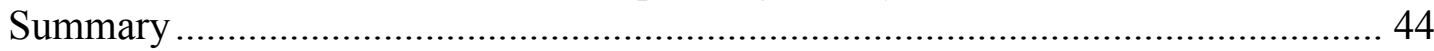

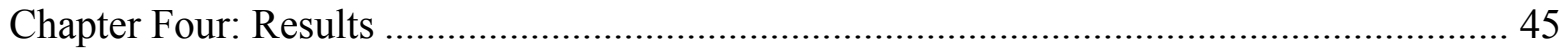

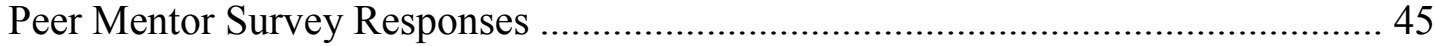

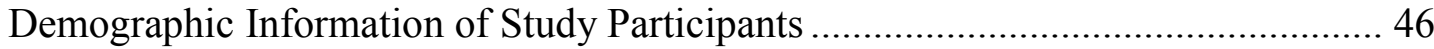

Results for Each Research Question ................................................................ 52

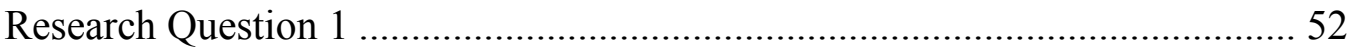

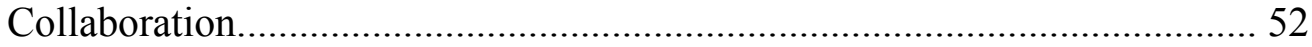

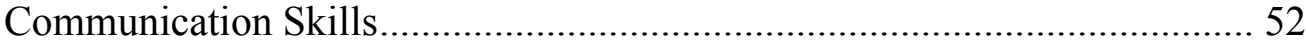

Decision-Making and Problem-Solving ............................................... 52

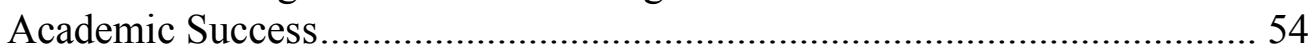

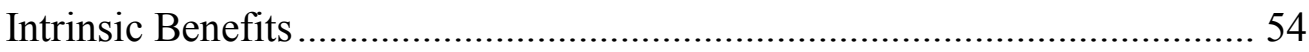

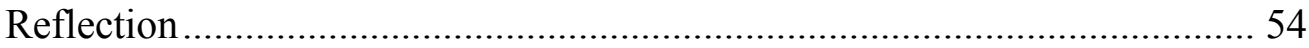

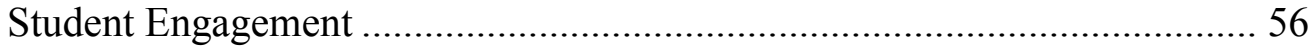

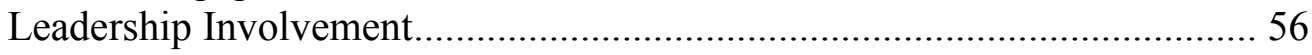

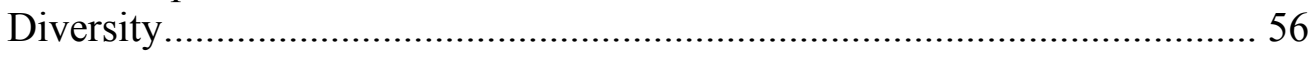

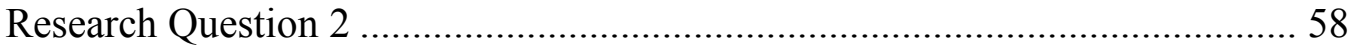

Satisfaction with the Mentoring Program Staff ........................................ 58

Satisfaction with Mentoring Experience.................................................. 58

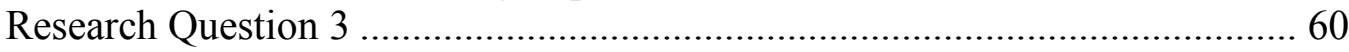

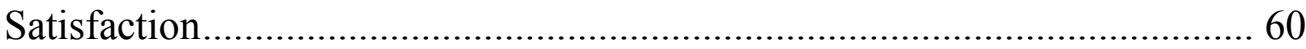

Satisfaction with Mentoring Program Staff, Based on Number of Years. 60

Satisfaction with Mentoring Experience, Based on Number of Years ..... 61

Perceived Learning and Development, Based on Number of Years ............ 62

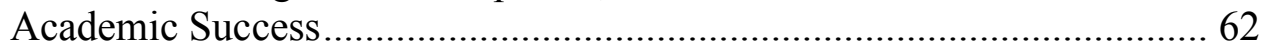

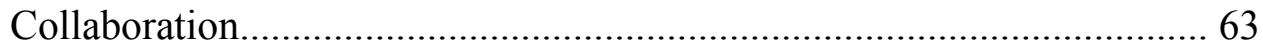

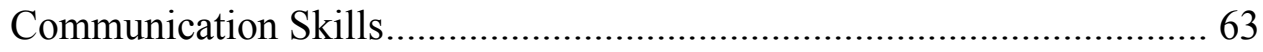

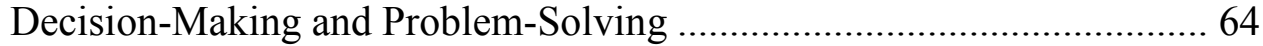

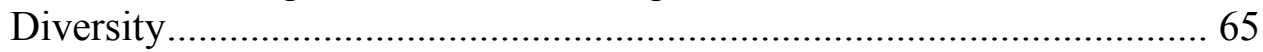

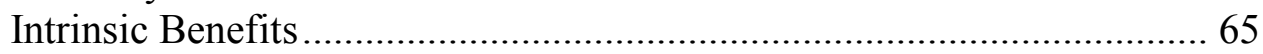

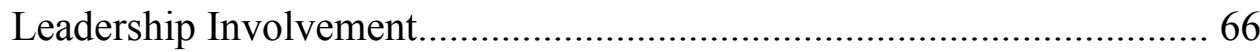

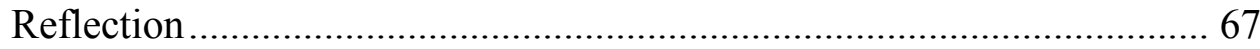

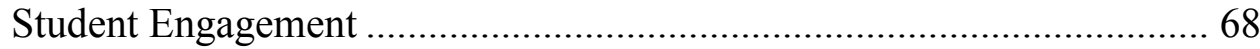

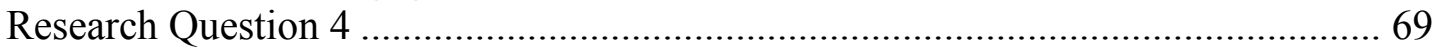

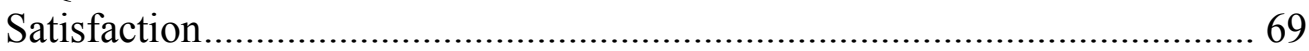

Satisfaction with Mentoring Program Staff, Based on College ............... 70

Satisfaction with Mentoring Experience, Based on College .................. 70

Perceived Learning and Development, Based on College.......................... 71

Academic Success ........................................................................ 71

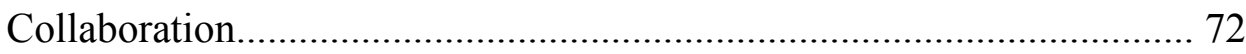

Communication Skills................................................................... 73

Decision-Making and Problem-Solving ........................................... 74

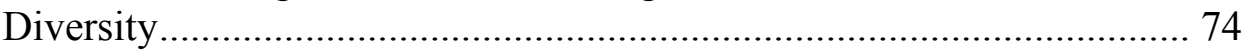




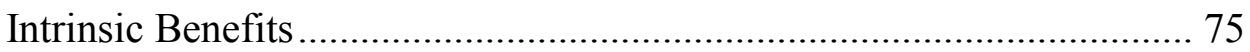

Leadership Involvement................................................................. 76

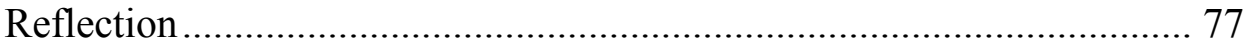

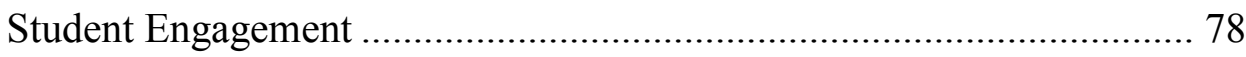

Summary of Key Findings …………………………….................................... 79

Chapter Five: Summary, Conclusions, and Recommendations......................................... 81

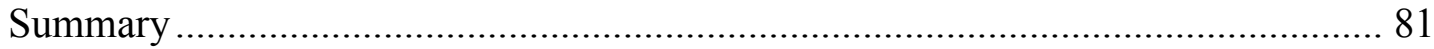

Conclusions: Learning and Development ............................................................. 83

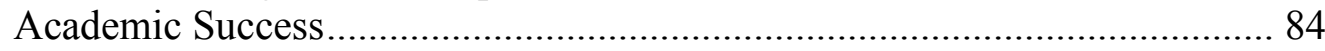

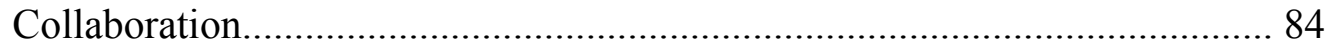

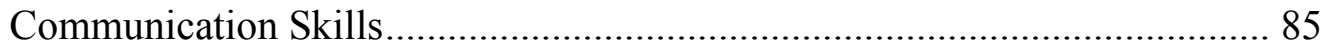

Decision-Making and Problem-Solving ......................................................... 86

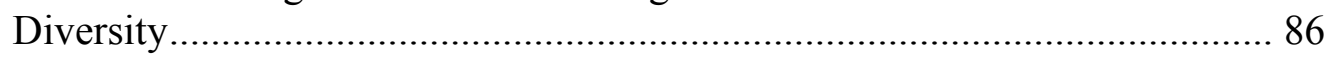

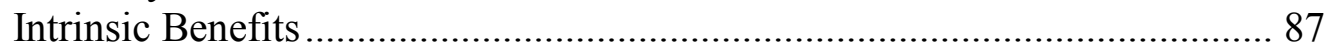

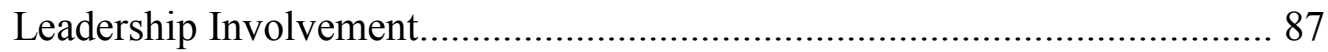

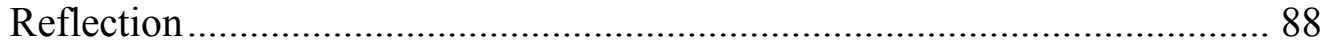

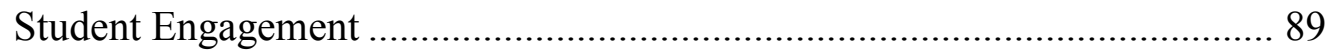

Conclusions: Satisfaction.................................................................................. 91

Satisfaction with the Mentoring Program Staff .............................................. 91

Satisfaction with the Mentoring Experience ................................................. 91

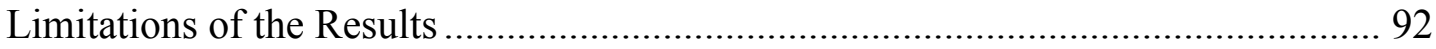

Implications for Practitioners and Future Studies.................................................... 93

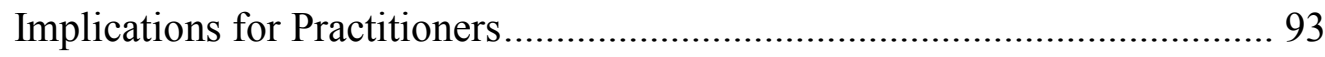

Recommendations for Future Studies ........................................................... 95

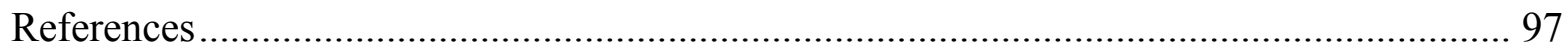

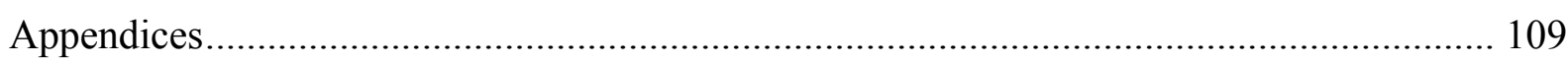

A. Letter to Request Institutional Site Approval and Pilot Approval ....................... 109

B. Letter from Institution Granting Permission for Pilot Study and Research.......... 111

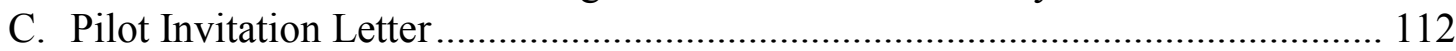

D. Survey Regarding Satisfaction, Learning, and Development of Peer Mentors in

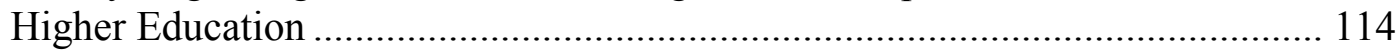

E. Interview Script for Pilot Study Participants ..................................................... 128

F. Student Participant Invitation Letter ................................................................... 129

G. Cover Letter for SurveyMonkey ${ }^{\mathrm{TM}}$................................................................. 131 


\section{List of Tables}

Table 1 - Research Questions with Corresponding Survey Items................................. 43

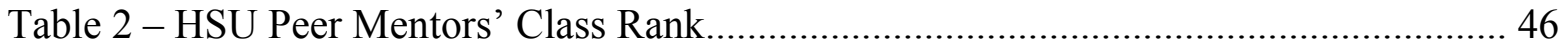

Table 3 - HSU Peer Mentors by Ethnic Identification ................................................ 47

Table 4 - HSU Peer Mentor Residential Status .......................................................... 48

Table 5 - HSU Peer Mentors who Live with Their Parents ............................................ 48

Table 6 - HSU Peer Mentors' Age .............................................................................. 49

Table 7 - HSU Peer Mentors' Marital Status ............................................................ 50

Table 8 - HSU Peer Mentors with Children ................................................................ 50

Table 9 - Number of Years HSU Peer Mentors Served as Peer Mentors .......................... 51

Table 10 - College Breakdown of HSU Peer Mentors.................................................... 51

Table 11 - Summary of Collaboration, Communication, and Decision-Making and Problem-

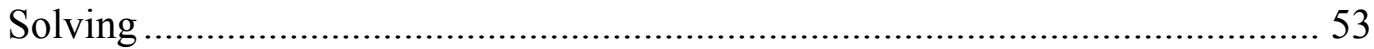

Table 12 - Summary of Academic Success, Intrinsic Benefits and Reflection................... 55

Table 13 - Summary of Student Engagement, Leadership Involvement, and Diversity...... 57

Table 14 - Summary of Peer Mentors' Satisfaction ................................................... 59

Table 15 - Satisfaction with Mentoring Program Staff, by Years................................... 61

Table 16 - Satisfaction with Mentoring Experience, by Years ....................................... 62

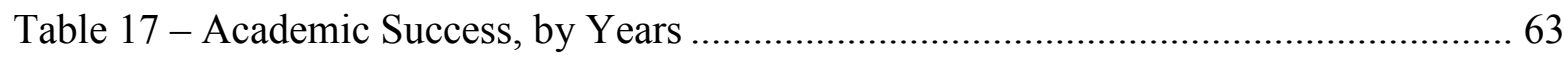

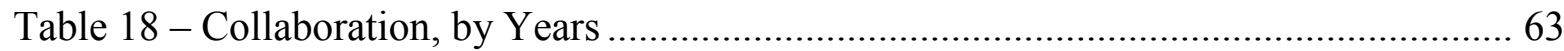

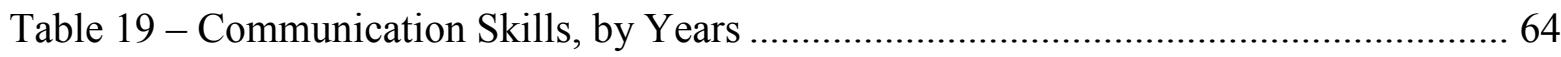

Table 20 - Decision-Making and Problem-Solving, by Years ..................................... 65

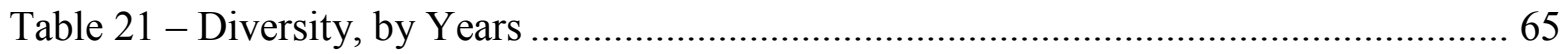




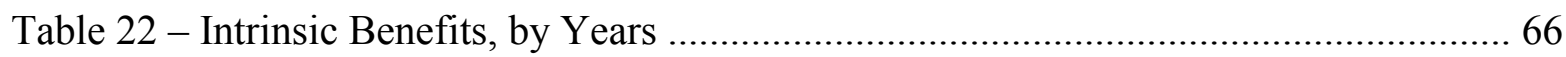

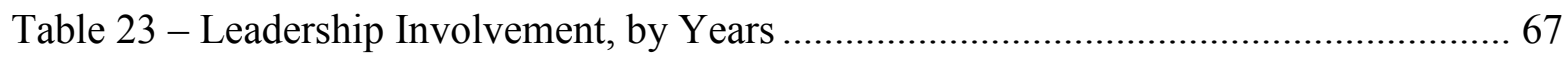

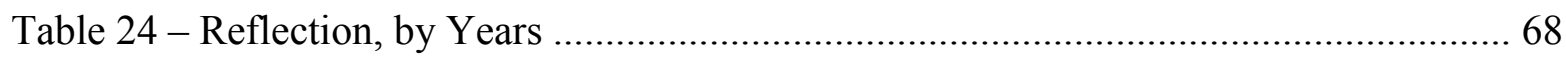

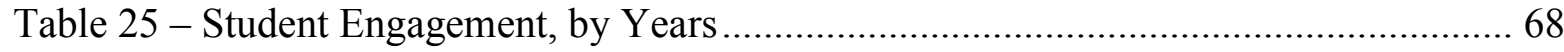

Table 26 - Satisfaction with Mentoring Program Staff, by College..................................... 70

Table 27 - Satisfaction with Mentoring Experience, by College ......................................... 71

Table 28 - Academic Success, by College ………………................................................... 72

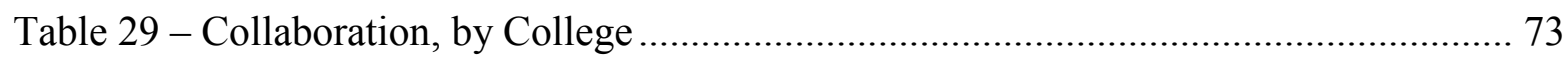

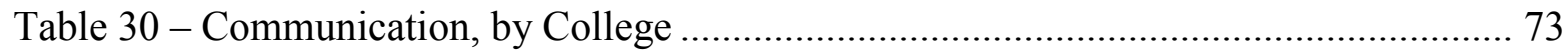

Table 31 - Decision-Making and Problem-Solving, by College …………………............... 74

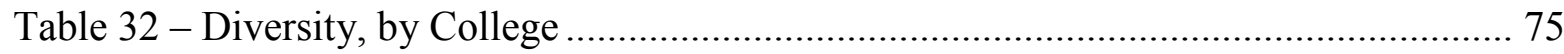

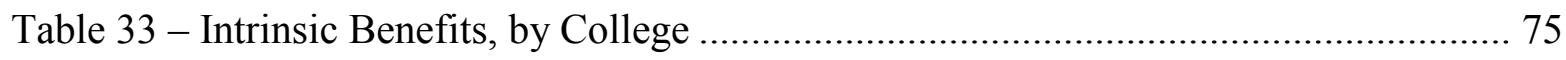

Table 34 - Leadership Involvement, by College ................................................................ 77

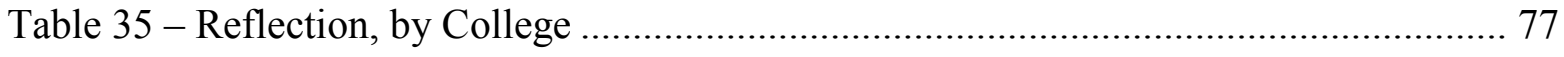

Table 36 - Student Engagement, by College ...................................................................... 78

Table 37 - Statistically Significant Differences, Based on Years .......................................... 90

Table 38 - Statistically Significant Differences, Based on College ...................................... 90 


\section{Chapter One}

\section{Introduction and Statement of Problem}

The concept of mentoring has been around for years (Cropper, 2000). Most researchers and practitioners agree that mentors provide guidance, give direction, and offer support to their protégés (Johnson, 2003; Weddington, 2006). Shea (1997) provides a definition that can apply to all aspects of mentoring. He states, "Mentoring is a fundamental form of human development where one person invests time, energy, and personal know-how in assisting the growth and ability of another person" (p. 3).

Mentoring programs typically have been established in management, community-based, and academic settings. However, the focus of this dissertation research study is on undergraduate peer mentoring programs in higher education for first-year college students.

With new traditions, rituals and expectations, freshmen may be overwhelmed with the new environment, feel frustration, rejection or a sense of isolation during their first year at college (Schulz, 1995). The 2008-2009 Consortium for Student Retention Data Exchange Report states that nearly 50 percent of student attrition occurs during the first year of college (Hayes, Wahlen, \& Cannon, 2009). Levitz and Noel (1990) further state that attrition decreases by 50 percent each following year. With such data on first year attrition, universities are implementing programs that focus on the educational successes and social and intellectual growth of first year students, with the intention of having a positive impact on student retention (Tinto, 1993). Such initiatives as first year seminar courses, pre-enrollment orientation, and learning resource centers assist students with the transition to college life (Habley \& McClanahan, 2004). Mentoring programs have also been an approach to assist students during their first year in college. 
Mentors may be faculty or staff members, but in many cases, universities are asking advanced students to serve as mentors to provide peer support (Terrion \& Leonard, 2007).

Kerr, Schulze, and Woodward (1995) indicate, "Research shows that the most appreciated benefit of the mentoring relationship is the encouragement, the „I know you can do it' support protégés receive, which in turn enhances their own self-confidence and motivation levels" (p. 36). However, mentoring is a relationship of two people that develops over time. Both individuals have a shared initiative and a willingness to invest their time, energy, and emotions into the relationship (Awe, 2003; Schulz, 1995).

Mentoring clearly benefits both people in the relationship. Not only do both the peer mentor and protégé benefit from sharing knowledge and enhancing decision-making skills, but there is also a mutual confirmation of self-worth and acceptance as a result of the interaction (Schulz, 1995). Awe (2003) exemplifies "no one ever leaves untouched whether it is the new skills the mentor has learned to apply or the „eureka!' insights the protégé gains and vice versa” (p. 37). Both the mentor and protégé gain personal enhancement, growth, and satisfaction, as well as improved communication skills (Schulz, 1995).

The research that examines university-based mentoring programs varies greatly. Researchers have conducted studies to examine certain outcomes such as student retention, enhanced academic success, postgraduate success or satisfaction of overall university experiences (Campbell \& Campbell, 2007; Crisp, 2009). Although these outcomes are valuable in providing evidence that mentoring programs have enhanced student success, it is difficult to isolate and attribute student success exclusively to the mentoring program (Johnson \& Sullivan, 1995). These outcomes also do not provide information as to whether students are learning and developing as a result of participation in the program (Bresciani, Zelna, \& Anderson, 2004). 
The structure of university-based peer mentoring programs varies from institution to institution. Some peer mentoring programs utilize paid mentors while others exclusively utilize volunteer mentors. Peer mentoring programs may provide extensive training to their mentors and have a required minimum interaction between mentors and their protégés; while other programs may be less formal in requirements of mentors and protégés (Crisp, 2009). These structures may influence student learning and development.

\section{Purpose of this Study and Research Questions}

This study examines student learning and development of student peer mentors from a peer mentoring program in higher education. The purpose of this study is to examine university peer mentors' perceived student learning and development. This study also examines peer mentors' satisfaction levels with the peer mentoring program and their peer mentoring experiences based on the college in which their major is housed (university college) and the number of years served as a peer mentor. The following research questions are addressed:

1. What learning and development occurs for students who serve as university peer mentors?

2. How satisfied are student peer mentors with (a) the mentoring program staff and (b) the mentoring program experience?

3. Is there a statistically significant difference by number of years experience as a peer mentor in (a) peer mentors' satisfaction with the mentoring program staff, (b) peer mentors' satisfaction with the mentoring experience and (c) peer mentors' perceived learning and development? 
4. Based on the peer mentors' university college (College of Education and Human Services; College of Science and Technology; College of Liberal Arts), is there a statistically significant difference in (a) satisfaction with the mentoring program staff, (b) satisfaction with the mentoring experience and (c) peer mentors' perceived learning and development?

The peer mentors in this study are predominantly residential students with $17 \%$ of peer mentors and protégés self-identifying as commuting students at this master's level, public university. Although the majority of the peer mentors and protégés are traditionally-aged (ages 18 to 24 ), two percent of these students self-identify as age 25 or older. Approximately $43 \%$ of new students (both freshmen and transfer students) request a peer mentor for their first year at this university.

\section{Significance of the Study}

Little quantitative research is available that examines university-based peer mentoring programs' learning and development of peer mentors. Therefore, this study explores the perceived learning and development of peer mentors in a university-based peer mentoring program. The results of this study contribute to evidence that students who serve as peer mentors may exhibit learning and development. This study also provides an instrument for practitioners to measure perceived learning and development. This study also provides insights into how peer mentors in different academic colleges perceive their overall mentoring experiences.

\section{Organization of the Dissertation}

In Chapter One, the researcher provided an introduction to this study, the statement of problem, and the significance of this study. The purpose of this study and research questions 
have also been described. In Chapter Two, the researcher describes mentoring and its role in higher education and student learning and development in higher education. In Chapter Three, the researcher describes and provides a rationale for the methodological approach for this study, including the setting, sample, and data collection procedures and analysis. A list of limitations of this study is provided within this chapter as well. In Chapter Four, the researcher reports the major findings. In the final chapter, the researcher provides a summary of the study, conclusions, and recommendations for future studies. 


\section{Chapter Two}

\section{Review of Literature}

The concept of mentoring has been around for years and has been integrated into various organizations to assist and guide new members into a new community. In higher education, mentoring has become an integral component in assisting new students as they transition to university life. This chapter provides an overview of the research on the concept of mentoring and its role in higher education.

This review of the literature is divided into several sections. First, a historical perspective of mentoring is presented, including how mentoring is defined and the role of mentors in a mentoring relationship. After mentoring is defined, a review of how mentoring is utilized in the community and education is discussed. Finally, a more detailed description of mentoring in higher education is provided with an explanation of the role of learning and development theories in enhancing mentoring experiences.

\section{Historical Perspective of Mentoring}

The word mentor dates back to Greek Mythology in The Odyssey. In Homer's classical myth, Odysseus must leave for his epic sea adventure and entrusts his son, Telemachus, to his friend Mentor. Mentor's role was to guide and advise Telemachus as he transitioned from boyhood to manhood (Conrady, 2007; Daloz, 1999; Harris, 2002; Murray, 1991; Ross-Thomas \& Bryant, 1994).

Today's mentors also provide direction and support that help a less-experienced person (also known as the protégé in a mentoring relationship) to successfully maneuver through a transition into a new and complex environment. Mentors share knowledge and real life experiences that inform protégés not only on how to do things right, but also how to avoid 
possible failure. By sharing personal successes and failures, mentors provide guidance and support to protégés concerning the path ahead (Cohen \& Galbraith, 1995).

Cohen and Galbraith (1995) describe the mentor-protégé relationship as a journey. The protégé travels through new surroundings as the mentor guides, encourages, and instructs the protégés. During this personal journey, the experienced mentor provides the necessary resources about what it takes to succeed and encourages the protégés to go beyond his or her own expectations (Schulz, 1995).

While mentoring existed for years, the level of interest in mentoring increased during the 1970s. In a 2007 review of the PsychINFO database, Campbell and Campbell (2007) found that prior to 1975, the word mentor "rarely appeared in an abstract" (p. 135). Since the 1980s, the word mentor appeared in anywhere from 15 articles per year to nearly 120 articles in the year 2005 (Campbell \& Campbell, 2007). These findings reinforce Jacobi's results of her 1991 ERIC database keyword search for the word mentor. According to Jacobi (1991, p. 506), ...the number of publications included in the ERIC database that include mentor as a keyword has risen steadily from only 10 references in 1978 to 95 references in 1988. Between January 1983 and December 1989, 492 references appear in response to this keyword, compared to only 111 between 1976 and 1982.

Although there has been a growing interest in mentoring, a distinct definition of mentoring still does not exist (Jacobi, 1991). Since Jacobi’s 1991 study, Crisp and Cruz (2009) found similar results. They identified over 50 definitions of mentoring which varied in "scope and breadth" (Crisp \& Cruz, 2009, p. 178). The definitions of mentoring have also been described as "too broad and strikingly inconsistent” (Johnson, 2003, p. 130). 
Overall, most definitions describe the mentor as an individual who provides information, support, and guidance to a less-experienced person who is often a new member to a particular environment. The purpose of the mentor/protégé relationship is to enhance the potential of the protégé's success (Campbell \& Campbell, 2007; Johnson, 2003). Kram’s (1988) mentoring research describes mentors as having two distinct functions: psychosocial and career-related. Psychosocial support is described as encouraging the protégé by helping them build self-esteem and confidence (Harris, 2002). Kerr, Schulze, and Woodward (1995) reinforce this description through their research, which states “...the most appreciated benefit of the mentoring relationship is the encouragement, the „I know you can do it' support protégés receive, which in turn enhances their own self-confidence and motivation levels" (p. 36).

By helping protégés with career-related issues, mentors provide insights into their professional experiences and share content knowledge that can help the protégé become familiar with a career (Harris 2002; Kram, 1988). Although Kram's writings focus on mentoring in the business world, these functions transcend to the various settings in which mentoring programs exist. Jacobi (1991) expands Kram's two mentoring functions by adding one more function: role modeling. Role modeling is seen as illustrating attitude and behaviors that others may emulate (Kram, 1988).

Despite the lack of a distinct definition, mentoring has become integrated into numerous organizations at the national, state, and local levels. The scope of the mentor and protégé relationships and the structure of mentoring programs vary from organization to organization (Girves, Zepeda, \& Gwathmey, 2005; Crisp, 2009). Mentoring can occur in an informal arrangement in which members of an organization naturally develop their own helping relationships without support or guidance from a program coordinator (Campbell \& Campbell, 
2000; Conrady, 2007). An example of an informal mentoring relationship could be what has been called "the old boys' network;" an informal arrangement in which a more experienced manager identifies a new employee to assist with the acclimation to the organization and prepare the new employee for future upper-level management positions. However, due to the historically smaller percentage of women and people of color in higher management positions, the informal mentoring design makes it difficult for women and people of color to naturally develop relationships with upper level managers (Cullen, 1993; Gonzalez-Rodriquez, 1995).

A formal or planned mentoring program can alleviate the exclusive membership that can occur in an informal mentoring arrangement. Through intentional recruiting, training, and matching of participants, formal mentoring programs can reduce the exclusiveness that an informal mentoring program can create; hence providing a more inclusive program for its members (Conrady, 2007; Single \& Muller, 2000). A formal mentoring program facilitates and develops effective mentoring relationships by offering guidance and support to both mentors and protégés (Girves, Zepeda \& Gwathmey, 2005).

Jacobi (1991) found that researchers disagree on whether formal mentoring programs are more effective than informal mentoring programs. Informal mentoring relationships are spontaneous and are based on "mutual attraction and free choice" (p. 512). However, due to the lack of well-designed assessment systems within informal mentoring programs, it is difficult to measure whether they are more effective than formal mentoring programs. As stated by Jacobi (1991), "Given the wide variety of formal mentoring programs coupled with the paucity of welldesigned evaluation research, speculation about this issue is all that is available at this time" ( $p$. 512). 
In a formal mentoring program, mentors are selected and trained. Those who will be mentored are also selected and instructed on the goals and mission of the program. Expected outcomes are created and a process to assess the outcomes is designed (United States General Accounting Office, 2004).

Mentoring can occur in a variety of ways. The traditional mentoring relationship model is a one-to-one, hierarchical relationship in which a more experienced person assists a less experienced person. Mentoring, however, is not limited to a dyadic relationship. For example, mentoring can be a network of people, each addressing a different facet of the protégé's life (Girves, Zepeda, \& Gwathmey, 2005; Packard, Walsh, \& Seidenberg, 2004) or mentoring can occur in a virtual setting via an on-line relationship (de Janasz, Ensher, \& Heun, 2008; Sinclair, 2003; Single \& Muller, 2000).

\section{Types of Mentoring Programs}

Mentoring programs exist in various settings, including community or educational settings. One of the best known community-based mentoring programs is Big Brothers/Big Sisters of America. The nearly 100-year-old community-based service program matches children to adult volunteers, serving approximately 75,000 children a year. The goal of Big Brothers/Big Sisters of America "is to help children reach their potential through professionally supported, one-to-one relationships with mentors that have a measurable impact on youth" (Tierney \& Baldwin-Grossman, 2000). The mentor engages in social events, such as taking the child out to eat, to a ballgame, to a concert, or taking the time to sit and chat with his or her protégé (Walker \& Freedman, 1996). The focus of this type of mentoring program is the psychological development of the child (United States General Accounting Office, 2004). 
Research conducted on education-based mentoring programs range from the early childhood setting (Peterson, Valk, Baker, Brugger, \& Hightower, 2010) to the college level environment. Mentoring programs in education can be designed to assist new teachers (Young \& Cates, 2010), faculty members (Ewing, et al. 2008; Gabriel \& Kaufield, 2008; Greene, et al. 2008), and administrators and staff (Hargraves, 2010) with their transitions to the educational setting. However, many of the mentoring programs in academic settings are designed to help students succeed. Mentoring programs for students within the educational system focus on not only the psychological development of the participants, but also the academic performance of the students (Bernstein, Rappaport, Olsho, Hunt, \& Levin, 2009).

Mentoring programs in higher education. Mentoring programs in higher education can be a first year initiative that helps new students with a successful transition to the university setting. The mentoring relationships offer a significant survival bridge through the very different world of academia. Mentors share "school-smart" knowledge and strategies that serve as valuable resources for freshmen to maneuver through and succeed in the college environment (Cohen \& Galbraith, 1995). By interacting with other members of the campus community and seeing that the community cares about them, these students are more likely to succeed. Overall, a well-designed mentoring program helps new students integrate into the new collegiate environment.

Students serving as peer mentors. Although faculty and staff have served as mentors to college freshmen, many university and college administrators are now asking undergraduate students to serve as peer mentors for the new students (Terrion \& Leonard, 2007). Peer mentors are students who just recently served in the role as freshmen. They are aware and can relate to the feelings experienced by uncertain freshmen because they often have experienced similar 
challenges including learning difficult material and needing stronger time management skills so that they can complete all the tasks expected of them. Peer mentors can help freshmen with the social adjustment to college life by inviting them to campus activities and introducing them to other students. Peer mentors also serve as role models (Allen, Russell \& Maetzke, 1997), which Jacobi (1991) states “... is of greatest importance to student development followed by emotional support and direct assistance" (p. 526).

The role of peer mentors. Peer mentors' roles are different at each institution, based on the goals and objectives of the particular university or college. For example, the University of Michigan's overall goal is to help new students find their niche at the university. They achieve this goal by providing a connection to the students and providing them with guidance and information on university resources (University of Michigan, 2010). Their peer mentoring program is offered to all incoming students. Other university administrators may also ask peer mentors to serve as tutors (Buffalo State University, 2010) or serve as a teacher's assistant in the first year experience class (DePauw University, 2010).

Selecting peer mentors. Mentoring Directors need to carefully select the students who will serve as peer mentors. These students have an important role in helping new students succeed during their time spent at the university. Therefore, all potential student peer mentors should participate in a formal screening and selection process based on criteria determined by the director of the mentoring program (Canton \& James, 2008). Overall, peer mentors need to have strong interpersonal skills and the ability and willingness to commit the time to help others. Knowledge of campus resources is also important. Thus, it is recommended that peer mentors have completed at least one year of university studies (Terrion \& Leonard, 2007). 
To qualify to serve as peer mentors, students should also have accomplished a level of academic achievement which gives them the credibility that they know how to academically succeed. However, students who previously struggled academically should not be disqualified to serve as peer mentors. Students who have faltered early in their academic career, but subsequently increased their grade point average can provide valuable information about study skills, time management skills, and describe to new students what works and doesn't work (Terrion \& Leonard, 2007).

Training is also an important component to successful mentoring relationships. Lack of training is reported as one of the major reasons mentoring relationships do not succeed (Ehrich, Hansford, \& Tennent, 2004). Training may include tips on establishing helping relationships, knowledge of student support services, knowledge of learning strategies (Terrion, Philion, \& Leonard, 2007), issues that may occur during a student's freshman year, and effective mentoring skills, such as communication skills and trustworthiness (Posa, 2009).

Recruiting protégés. Some university mentoring programs focus on providing mentors to specific at-risk populations. In these mentoring programs, protégés are identified based on such issues as socio-economically disadvantaged backgrounds, low SAT scores or possibly underrepresented ethnic groups (Campbell \& Campbell, 2007; Harter \& Jones-Walker, 2000), while other university mentoring programs may encourage all new students to participate (Campbell \& Campbell, 2007). Mentoring programs that offer peer mentors to all incoming students focus on helping new students assimilate into the university environment. Students are typically invited to participate in the program upon acceptance to the university and are reintroduced to the mentoring program during summer orientation activities (Campbell \& 
Campbell, 2007). In this type of program, the new students are self-selected and individually determine whether or not they would like to partake in the program.

Matching protégés with peer mentors. Matching can be a key element of a successful relationship and can have a positive impact on the satisfaction levels of the participants (Terrion \& Leonard, 2007). When matching protégés to mentors, various factors are taken into consideration, including program of study, race, gender, residential living or commuting, and overall interests of the participants (Canton \& James, 2008).

McLean (2004) found that protégés with peer mentors from the same program of study share similar experiences and hence can be seen as a reliable source. Protégés who are assigned peer mentors from the same program of study also report greater satisfaction with the mentoring relationship than protégés with mentors from other academic programs (McLean, 2004).

It is also worth noting that although many higher education institution administrators take into consideration gender and ethnicity when matching peer mentors with protégés, Campbell and Campbell (2007) found that less than $1 \%$ of the mentors or protégés participating in a mentoring program at a large metropolitan university in California actually requested that their match be of the same gender or ethnic background.

Longevity of the peer mentoring relationship. The mentoring relationship in many firstyear mentoring programs is intended to be a one-year experience, with the hope that the mentors maintain contact with their protégés beyond the minimum one year expectation (Campbell \& Campbell, 2007, Jacobi, 1991). However, in a self-selected mentoring program, the peer mentors and their assigned protégés determine how often and how much time they will meet depending on the issues the participants wish to work on (e.g., time management, preparing for registration, presentation rehearsal, etc.) (Sweet Briar College, 2010). 


\section{Student Learning and Development}

Universities have been traditionally organized by two areas: academic affairs and student affairs (American College Personnel Association, 1996). Academic affairs primarily focused on the cognitive development of students, while student affairs primarily focused on affective development of students (American College Personnel Association, 1996). With this mindset, it is often assumed that cognitive development occurs exclusively within the classroom environment. However, it is now known that students are exposed to learning opportunities through interactions with various individuals in- and out-of-the classroom setting (American College Personnel Association, 1996). When examining student learning, the American College Personnel Association (ACPA) perceives that “the concepts of ,learning,', ,personal development,' and ,student development' are inextricably intertwined and inseparable” (ACPA, 1996, para. 6). Organizations, such as ACPA and the National Association of Student Affairs Administrators in Higher Education (NASPA) do not want to infer that "learning and student development are fundamentally different things, or that one does, or could, occur without the other" (Keeling, 2004, p. 4).

In 1996, ACPA developed the Student Learning Imperative: Implications for Student Affairs, in which they proclaim there are five hallmarks of a college educated person: (1) complex cognitive skills such as reflection and critical thinking; (2) an ability to apply knowledge to practical problems encountered in one's vocation, family, or other areas of life; (3) an understanding and appreciation of human differences; (4) practical competence skills (e.g., decision-making, conflict resolution); and (5) a coherent, integrated sense of identity, self-esteem, confidence, integrity, aesthetic sensibilities, and civic responsibility. (ACPA, 1996, para. 5) 
These traits are a combination of cognitive, affective, and behavioral growth and development. Student development practitioners focus on the whole student by assisting with the growth and development of students in these areas in outside-of-the-classroom experiences (Evans, Forney, \& Guido-DiBrito, 1998).

In 1998, the Joint Task Force on Student Learning further describes learning as a developmental and cumulative process in which connections are made and maintained biologically, mentally, and experientially. Students go through these developmental phases in the same sequence; however, the student's age and the rate at which they pass through the phases vary (Evans, Forney, \& Guido-DiBrito, 1998). Theorists, such as Baxter Magolda, further found that "over time, students change not only in terms of what they know, but also in terms of how they know" (Huba \& Freed, 2000, p. 50). As they develop, students begin to understand how knowledge is acquired and create strategies for learning based on their strengths and limitations (Joint Task Force, 1998).

The Council for the Advancement of Standards in Higher Education (CAS) has also been instrumental in promoting “...the assessment and improvement of higher education services and programs through self-study, evaluation, and the use of CAS standards" (Miller, 2003, p. 2). The CAS standards provide a guideline for student affairs practitioners to measure students' learning and development. Although CAS does not have an assessment designed specifically for mentoring programs, they identify functional areas of practices that are common to most divisions (Miller, 2003). In 2002, the CAS Board of Directors adopted a revision of CAS that placed increased emphasis on “....achievable, observable, and assessable outcomes associated with student learning and development" (Miller, 2003, p. 17). Within this revision, 16 specified student learning and development outcome domains were created and “... are viewed as highly 
desirable for all functional areas to pursue" (Miller, 2003, p. 17). However, in the 2009 edition of CAS, the student learning and development outcomes were adapted in response to Learning Reconsidered 2 (2006). Instead of the 16 student learning and development outcome domains, CAS now has six broad learning and development student outcome domains. The new domains are: 1) knowledge acquisition, constructions, integration and application; 2) cognitive complexity; 3) intrapersonal development; 4) interpersonal competence; 5) humanitarianism and civic engagement; and 6) practical competence (Dean, 2009).

Learning and development of the peer mentors. Cohen and Galbraith (1995) describe the mentoring experience as a journey for the protégé. The metaphor is used because the protégé, as a learner, is on a journey of self-development. However, mentoring should be seen as a mutual relationship with both individuals having a shared initiative and a willingness to invest their time, energy, and emotions into the relationship. Therefore, it should not be surprising that both the peer mentor and protégé contribute to the personal growth, development and empowerment of each other (Schulz, 1995; Liu, Liu, Kwan, \& Mao, 2009). Hence, the peer mentor is also on a journey of personal growth and development.

Peer mentor training and the interaction with their protégés provide opportunities for peer mentors to learn and develop. Training is designed to develop the knowledge and skills of the peer mentors, to not only help them to become effective mentors, but also to enhance their own academic and personal successes (Terrion, et al., 2007). In a qualitative study of peer mentors for first-year students at Valdosta State University, Harmon (2006) found that through participation in peer mentor training programs, peer mentors increased their competence "...in areas of personal development such as leadership, knowledge concerning relevant content of peer education programs, and personal health behaviors" ( p. 58). 
In addition to benefits obtained through the training process, protégés can enhance their own skills through their repeated interactions with their protégées that gives them opportunities to refine their skills over time. Harmon (2006) indicated that peer mentors recognized, “...the qualities and skills they gained from being a part of the program" (p. 69). He found that the mentoring experience "led mentors to think beyond the confines of their specific majors and discover broader applications of what they learned" (p. 76). Serving in the role of peer mentors provides students with practical experience and skills that can be transferred to their college major or future employment (Harmon, 2006). Employers view transferable job skills, such as communication, problem solving, teamwork and leadership as essential for job seekers (Carnevale, Gainer, \& Meltzer, 1990; Hansen \& Hansen, 2011). For example, in the mentoring literature, there is discussion on the need for mentors to effectively communicate in a mentoring relationship (Allen \& Poteet, 1999; Harris \& Crocker, 2003; Heirdsfield, et al., 2008; Mee-Lee \& Bush, 2003; Terrion \& Leonard, 2007). CAS identifies “communicating effectively" as a dimension of the practical competence domain of student learning and development (Dean, 2009, p. 28). The continuous engagement and interaction between the mentors and protégés provides opportunities for peer mentors to improve their communication skills, particularly their interpersonal communication skills (Harmon, 2006). Jones and Kolko (2002) found that student peer mentors at Indiana University expressed more confidence in their communication abilities.

In a study of experienced teachers who served as mentors to new teachers, Gilles and Wilson (2004) found that mentors strengthened their leadership skills. On college campuses, peer mentors are seen as leaders. Being selected to serve in the role of peer mentor implies that the student has the potential skills and abilities to assist others (Conrady, 2007). Therefore, many peer mentors are often selected to serve in various leadership roles. 
The 2009 edition of CAS emphasized the importance of students engaging in activities and organizations that provide opportunities for "involvement with people who are different from oneself' (Dean, 2009, p. 27). University peer mentoring programs provide opportunities for students to be introduced to new cultures and diverse ideas. Peer mentors work with students who have different issues and concerns with diverse learning styles and developmental levels of understanding. Peer mentors ideally understand and appreciate the differences of each of their protégés and adapt to each individual's strengths and weaknesses (Harmon, 2006). Harmon (2006) found that the peer mentors identified that in their role as peer mentors, they learned how to interact with diverse groups of students and learned to identify personal needs and learning styles of their protégés. The peer mentors learned to adapt their mentoring approach to address the various issues and concerns of each student they assisted (Harmon, 2006).

Collaboration is an important component for the growth and development of college students. In the 2009 edition of $C A S$, collaboration is a dimension of the interpersonal competence domain of student learning and development. This domain encourages students to work “cooperatively with others" (Dean, 2009, p. 27). Peer mentor training provides an opportunity for peer mentors to not only reinforce skills, but also to establish networks and offer a venue for engagement with fellow students, faculty and other professionals throughout the university (Terrion, et al., 2007). Many mentoring programs conduct on-going group training meetings with the peer mentors. As a result of meeting on a regular basis, the students become part of a learning community with fellow peer mentors who learn from each other on how to problem-solve and how to prevent potential conflict (Harmon, 2006; Terrion, et al., 2007). In the Harmon (2006) study, peer mentors indicated that they worked collaboratively with fellow peer mentors to learn from each other about effective mentoring strategies. In a study of peer mentors 
for first-year teacher education students conducted at Queensland University of Technology, Heirdsfield, Walker, Walsh and Wilss (2008) found that "some mentors described a greater selfawareness of the need to discuss information with others to arrive at solutions to problems" (p. 115). Overall, these meetings help mentors create networks with each other to establish an academic and social support system (Heirdsfield, et al., 2008).

Training is designed to develop the knowledge and skills of the peer mentors, to not only help them to become effective mentors, but also to enhance their own academic and personal successes (Terrion, et al., 2007). In the study conducted by Terrion, Philion, and Leonard (2007) of the University of Ottawa's peer-mentoring training program, peer mentors indicated an increase in their individual competencies in areas such as understanding of university resources and learning strategies after completing peer mentor training. The peer mentors indicated that due to increased awareness of campus resources, they utilized the university's student support services more often and hence, enhanced their own learning skills (Terrion, et al., 2007). Heirdsfield, et al., (2008) had similar findings. Peer mentors from the Heirdsfield, et al. (2008) study indicated that peer mentors were more aware of university information and resources that also could be beneficial to not only their protégés, but also to them. In addition, the heightened awareness of their personal learning styles had a positive impact on peer mentors' own time management skills, study habits, and social interactions (McKinney \& Reynolds, 2002).

Student engagement and peer mentors. Involvement in university experiences (both in and outside of the classroom) is an important component to the growth and development of students (ACPA, 1996). According to Kuh (2005), “After controlling for student background characteristics (such as ability and academic preparation), the student development research indicates that a key factor in student success is student engagement" (p. 87). Kuh (2005) defines 
student engagement as "the amount of time and effort students put into their studies and other educationally purposeful activities" (p. 87). Astin (1984) found the amount of time and effort a student gives to an activity has a strong correlation to the amount of development and learning that occurs. Overall, student involvement is determined by what an individual actually does and how he or she behaves, not by intentions or attitudes towards involvement (Astin, 1984; Berger \& Milem, 1999; Foubert \& Grainger, 2006).

Providing an enriching learning environment that facilitates learning and personal growth will help students to discover and develop their talents and abilities and keep them engaged and excited about learning (Levitz \& Noel, 1990). Chickering and Reisser (1993) indicate that the educational environments, including engagement with faculty and fellow students influence student development during college.

University peer mentoring programs that match freshmen with peer mentors in the same academic major create a sense of community. Within the academic department, peer mentors can be instrumental in introducing freshmen to faculty and fellow students within the same academic community, thereby increasing a sense of inclusion, academic engagement, and hopefully enhancing congruence for the freshmen. In addition, such designs also enhance peer mentors' departmental recognition amongst faculty and their peers as leaders within the department. Faculty and administrators can also play a critical role in the learning environment. By serving as role models in teaching and leadership, setting high expectations, and providing encouragement, university faculty and administrators can be influential in the growth and development of college students (Chickering \& Reisser, 1993). According to the study conducted at University of Ottawa by Terrion, Philion, and Leonard (2007), peer mentors who 
participated in the mentoring program indicated that they felt more connected to the university faculty.

Peer mentors and reflection. Within the structure of many mentoring programs, peer mentors are encouraged to reflect on their interactions with their protégés and their own learning (Harmon, 2006; Heirdsfield, Walker, Walsh \& Wilss, 2008; Terrion, et al., 2007; Zachary, 2000). Zachary (2000) in her book, entitled The Mentor's Guide: Facilitating Effective Learning Relationships, emphasizes the importance of reflection in a mentoring relationship. She describes that:

Critically reflective mentors find that they are more focused in their mentoring relationships. They bring expanded energy, take more informed action, and are generally more satisfied with their mentoring relationship. They also experience a carry-over to their personal and professional relationships as the habit of critical reflection becomes internalized. (p. 162)

In the 2008, Heirdsfield, et al. (2008) study, peer mentors were asked to document their mentoring experiences as reflections. This study found that peer mentors indicated that through reflections of their mentoring training and subsequent mentoring relationship, they became more aware of their own competencies and study skills (Heirdsfield, et al., 2008).

In a 2003 study conducted by Harris and Crocker of on-campus mentors in a university principal preparation program in Texas, they found that the most frequent learning cited by the mentors was "the opportunity to reflect on practice and increase their understanding of practice" (p. 77). Ehrich, Hansford, and Tennet (2004), in an analysis of more than 300 research-based articles on formal mentoring programs, identified reflection as the second most frequently cited outcome for mentors. 
Through personal reflections, peer mentors examine their own experiences and processes which provided them with more insightful explanations on how to approach situations (Conrady, 2007; Harris \& Crocker, 2003). In addition, through self-reflections, peer mentors also evaluate what works and doesn't work with each protégé and determine how to interact with various people with different values and backgrounds (Liu, et al., 2009).

Intrinsic benefits for peer mentors. Researchers found that peer mentors gain a sense of self-worth when they receive gratitude from their protégés (Gilles \& Wilson, 2004; Heirdsfield, et al., 2008). Due to participating in mentoring relationships, peer mentors report increased competence, enhanced feelings of confidence in their own abilities, and esteem among peers (Allen, Russell, \& Maetzke, 1997). A study conducted at Indiana University by McKinney and Reynolds (2002) found that peer educators reported higher levels of confidence since serving in this peer leadership role. Students from this study expressed their belief that they were making a difference by helping other students. They also stress their increased confidence due to their heightened awareness of support services and indicated they would more likely seek support (McKinney \& Reynolds, 2002).

\section{Satisfaction and Peer Mentors}

Individuals who serve in the role of peer mentor describe it as a satisfying experience (Heirdsfield, el at., 2008; Mee-Lee \& Bush, 2003). A study of in-depth interviews of mentors from various organizations found that mentors had enhanced satisfaction in observing others succeed (Allen, Poteet, \& Burroughs, 1997). In a study conducted in England of nursing mentors who helped nursing students, the mentors stated they had a "sense of personal satisfaction from facilitating students' learning...” (Atkins \& Williams, 1995, p. 1011). 
In a review of the literature by Ehrich, Hansford, and Tennet (2004), personal satisfaction, reward, or growth was one of the most frequently cited outcomes for mentors. In a similar manner, McLean (2004) found that mentors indicated the mentorship experience was rewarding because they helped others succeed and developed potentially long-term friendships. An eight case-study evaluation of a peer mentoring program in secondary schools in England found that when asked about their experiences, peer mentors indicated that they were pleased to serve as peer mentors and were also satisfied with the preparation provided to them to serve in this role (Knowles \& Parsons, 2009).

\section{Conclusion}

Overall, peer mentoring programs benefit both protégés and mentors. Peer mentors are provided with various opportunities to learn and develop. Through participation in a mentoring program and the interaction with their protégés, the peer mentors ideally reflect, problem-solve, acquire transferable skills, understand and appreciate human differences, collaborate, and obtain practical competency skills.

\section{Definition of Terms}

Peer Mentor - In the context of this study, the mentor is a college student who provides guidance, knowledge and support to a college freshman within the same academic department. Protégé - In the context of this study, a protégé will be defined as a university freshman who is assigned an upper-division student who will serve as their peer mentor.

Mentoring - Overall, mentoring is defined as the relationship of a more-experienced individual providing information, support and guidance to a less-experienced person who is often a new member to a particular environment. The purpose of the mentor/protégé relationship is to enhance the potential of the protégé's success (Campbell \& Campbell, 2007; Johnson, 2003). 
Learning - The acquisition of knowledge, skills, attitudes as a result of participation in a learning experience (Suskie, 2004).

Development - Rodgers (1990) defined student development as "the ways that a student grows, progresses, or increases his or her developmental capabilities as a result of enrollment in an institution of higher education" (p. 27).

Satisfaction - Satisfaction occurs when expectations are met or exceeded by the students' perceptions of the campus reality (Schreiner \& Juillerat, 1994). For the purpose of this study, satisfaction refers to whether peer mentors' expectations of the mentoring program were met or exceeded. 
Peer Mentors' Learning and Development 26

\section{Chapter Three}

\section{Methodology}

Many peer mentoring programs in higher education are designed to help freshmen with the transition to university life. This approach is beneficial in helping new students during their first year of college (Kerr, Schulze, and Woodward, 1995). However, both the mentor and protégé are invested in the mentoring relationship; therefore, it is not surprising that mentors also benefit from being involved in the relationship (Awe, 2003; Schulz, 1995). Mentors have described intrinsic benefits, such as increased self-confidence and self-worth (Schulz, 1995). However, there is little quantitative research on learning and development of peer mentors. Therefore, the purpose of this quantitative study is to examine university peer mentors' perceived student learning and development. In addition, this study also examines peer mentors' satisfaction levels with the peer mentoring program and their peer mentoring experiences based on the college in which their major is housed (university college) and the number of years of serving as a peer mentor.

In this chapter, the researcher describes and provides a rationale for the methodological approach for this study. This chapter contains information on the research design, including the site selection and profile, the sampling procedure, the data collection procedure and survey instrument, and data analysis. The limitations of this study are also provided within this chapter as well.

\section{Research Design}

Quantitative methods were utilized to conduct descriptive research throughout this study. Descriptive research is utilized to collect data "to test hypotheses or answer questions concerning 
the current status of the subject of the study" (Gay, 1996, p. 249). According to Gay (1996), "a descriptive study determines and reports the way things are" (249).

The researcher developed a survey instrument containing items addressing learning, development, and satisfaction that was administered to peer mentors from a university-based mentoring program. "A survey design provides a quantitative or numeric description of trends, attitudes, or opinions of a population by studying a sample of that population (Creswell, 2003, p. 153). The results of the survey research can provide inferences about the total population (Patten, 2002).

A Likert scale was developed to measure learning, development, and satisfaction of the peer mentors. The Likert scale is used to obtain attitudes or opinions. "The scale is a more refined tool that forces the respondent to give opinion on a series of statements..." (Hek \& Moule, 2006, p. 81). This researcher utilized the following levels of intensity dimensions: strongly agree, somewhat agree, neither agree nor disagree, somewhat disagree, strongly disagree.

According to Suskie (1996), the Likert scale is "easy to complete" and "efficient" (p. 33). In addition, the results of the survey can be easily converted into quantitative data. The survey consists of 27 items that address learning and development of the peer mentors. An additional eight questions addressed the satisfaction of the peer mentors. An on-line survey, utilizing SurveyMonkey ${ }^{\mathrm{TM}}$, was administered to the population of peer mentors at a public, comprehensive, master's state university located within the Northern portion of the Appalachian Mountains. An on-line survey provides convenience to the participants and is cost efficient. 


\section{Research Method}

This section of Chapter Three describes the selected site, the sampling procedure, the data collection and survey instrument, the limitations of this study, the data analysis and the results of the pilot study.

Site selection and profile. Hillview State University (HSU) (fictitious) is classified by the Carnegie Foundation as a public, "Master's Colleges and Universities, Larger Programs" which enrolls approximately 9,000 full-time students (Carnegie Foundation, 2011). Approximately 7,200 students are enrolled as undergraduate students and 1,800 are enrolled as graduate students. HSU oversees campus housing for nearly 2,300 students with 1,200 additional students living in off-campus housing in the surrounding community.

The design of peer mentoring programs across the United States differs based on the goals and objectives of the university. In some institutions, a peer mentor is offered to all incoming students (University of Michigan, 2010). While in other cases, peer mentors may serve as tutors (Buffalo State University, 2010) or assist in the first year experience class (DePauw University, 2010). In addition, peer mentors may be paid or serve as volunteers. Also, peer mentoring programs may provide extensive training to their mentors and have a required minimum interaction between mentors and their protégés; while other programs may be less formal in requirements of mentors and protégés (Crisp, 2009).

At Hillview State University (HSU), the peer mentor model is designed to help new students with the transition to the university by providing early and continual communication between peer mentors (upper-division students) and incoming students (both freshmen and transfer students). In this university-based peer mentoring program, all new students are invited to participate in the program. New students are not required to have a peer mentor assigned to 
them; however, over 900 new students request a peer mentor each year (which is approximately $45 \%$ of the new student population at HSU).

Each year, approximately 700 students are trained to serve as volunteer peer mentors. Students who serve as peer mentors are in good academic and disciplinary standings at the university. HSU's peer mentoring program strives to recruit students that represent all academic majors and the various demographic backgrounds of the student population, such as race, gender, and age.

HSU's peer mentoring program is a departmentally-based program with each peer mentor assisting one to two new students within the same academic department. For example, if a new student majoring in business requests a mentor, an upperclass student majoring in business will be assigned as a peer mentor to the new student. Students who volunteer to serve as peer mentors at HSU represent all undergraduate academic majors at the university. Peer mentors from the same academic department provide protégés with both psychosocial and career-related benefits, which enhance confidence and professional development (Girves, Zepeda, \& Gwathmey, 2005; Packard, Walsh \& Seidenberg, 2004). In addition, a departmentally-based peer mentoring program can help to facilitate a sense of community with faculty, current students and new students within the academic departments.

The peer mentors in HSU's program are all volunteers and are required to attend a twohour face-to-face training workshop only one time. If concerns arise with individual peer mentors, one-to-one additional training is provided to address specific issues. The peer mentoring program's training includes discussion of issues that may occur during a student's freshman year, ways that a peer mentor can help freshmen with the transition to the university, and effective mentoring skills, such as communication skills and trustworthiness 
In addition, the peer mentoring program's staff members provide ongoing training weekly via emails that describe the developmental needs of freshmen. The emails also provide timely procedural information needed by first-year students, such as deadlines, posting of midterm grades, and course registration processes. Peer mentors are informed to use the weekly emails as a guide to assist their protégés.

The senior administrators at HSU support the concept of peer mentoring and have created a centralized mentoring program office that is staffed to oversee the development and continuous implementation of a campus-wide peer mentoring program. HSU's peer mentoring program consists of a director, assistant director, secretary, graduate assistant, and fifteen work study students. The program is highly visible on campus and has the support of the senior administrators, faculty, staff, and students.

HSU sees facilitating the mentor/protégé match as an essential component of a successful mentoring relationship. Therefore, each of the fifteen work study students is assigned specific academic departments. These students are responsible for facilitating the relationships between the mentors and protégés and identify potential problems that need to be addressed. The work study students maintain regular contact with the mentors and the protégés to answer questions and to ensure the relationships between the mentors and protégés are successful.

Because the peer mentors are volunteers, the level of mentor-to-protégé interaction is determined between the mentor and the protégé in each mentoring relationship. However, peer mentors are "strongly encouraged" to communicate with their protégés weekly and to meet with them face-to-face on a monthly basis during the fall and spring semesters. Some of the academic department faculty members also organize gatherings with mentors and protégés at the beginning of the semester to introduce the new students to the department. In addition, some faculty 
members also organize group meetings with the department mentors and protégés during the registration period.

This site was selected for several reasons. HSU's peer mentoring program has been in existence for nearly 12 years. HSU's peer mentoring program has an extensive number of peer mentors who are not paid. HSU reports that freshmen with peer mentors have progressed to their sophomore year at an average of a $10 \%$ higher rate than freshmen without peer mentors. Another reason for selecting this peer mentoring program is that it is available and open to students in every academic department on campus.

Participants. The participants in this research are undergraduate students enrolled in HSU currently serving as peer mentors. The students in this study served as volunteer peer mentors during the fall 2010 and/or spring 2011 academic year.

All peer mentors who were assigned a protégé and provided updates on meetings with their protégé during the fall 2010 and/or spring 2011 peer mentoring program were asked to complete a survey to participate in the research study. The total population was 600 peer mentors. Participation in the study was voluntary and individual responses remained confidential. A response rate of $50 \%$ or better was desired.

Data collection and survey instrument. The researcher collected data in the spring semester of 2011 at HSU. Initially, the researcher requested (Appendix A) and received permission from Hillview State University's Provost (Appendix B) to allow HSU's students to participate in the study, received approval from the West Virginia University (WVU) Institutional Review Board for the Protection of Human Subjects (IRB) and HSU's IRB was approved. Once IRB approval was granted, a pilot study was conducted. 
Pilot study results. Six Hillview State University (HSU) alumni who previously served as peer mentors in the HSU peer mentoring program were sent an invitation letter (Appendix C) to complete the Survey Regarding Satisfaction, Learning and Development of Peer Mentors in Higher Education (Appendix D). The survey was administered via on-line technology utilizing SurveyMonkey ${ }^{\mathrm{TM}}$. The survey consisted of three sections: demographic items, learning and development items, and satisfaction items. The pilot study had two primary purposes. First, the pilot would identify potential errors that would occur within the on-line system. Next, the pilot was used to determine adequacy of the research instrument and to assess the feasibility of the survey instrument.

The six HSU alumni selected for the pilot study represented three undergraduate university colleges: College of Education and Human Services; College of Science and Technology; and College of Liberal Arts. Two of the participants graduated with a degree within the College of Education and Human Services; two of the participants graduated with a degree with the College of Science and Technology and two of the participants graduated with a degree within the College of Liberal Arts. All graduated from HSU within five years of partaking in the pilot study. The pilot subjects were selected based on university college, convenience, and availability. The participants of the pilot study were not included in the full dissertation study. The identity of these respondents is protected.

Once the pilot study participants completed the survey, the researcher contacted each of them individually to conduct phone interviews. Each participant was asked the following openended questions (Appendix E).

1. Approximately how long did it take for you to complete the survey?

2. Did you have any difficulties entering and completing the survey? Please explain. 
3. Do you have recommendations on how to make the survey easier to complete? Please explain.

4. Were the items clear and easy to understand? Please explain.

5. Do you have recommendations on how to improve the items? Please explain.

6. If a random drawing were held for a prize for participants who complete the survey, what prize would you recommend within the price range of $\$ 20$ to $\$ 200$ ?

When responding to the first question, "Approximately how long did it take for you to complete the survey?" on average, the participants responded that the survey took five to fifteen minutes to complete. All of the pilot participants indicated that they did not have any difficulties entering or completing the on-line survey.

All of the respondents indicated that the survey items were clear and easy to understand. Participants were asked how the survey could be easier to complete. One respondent preferred having a section to provide additional information on her response. The researcher decided this was not an appropriate area to change. Another respondent felt the item which was a negativelyworded stem would create a problem for those who would not carefully read the question. She requested that the word "no" in survey item 42 be emphasized through capitalization. The word "no" in survey item 42 was capitalized.

Respondents were asked how individual survey items could be improved. A respondent recommended clustering together the statements that referred to interaction with protégés. Survey item 22 from the pilot study, which stated, "I am better able to help others in their decision-making and problem-solving processes," was relocated to align with other survey items that referred to interaction with their protégés in survey item 19. The remaining pilot participants indicated that they did not have any recommendations for improvement. 
When asked what prizes they would recommend for a random drawing, all of the respondents indicated that a gift card ranging from $\$ 20$ to $\$ 50$ would be the best option. Two respondents stated that offering more random drawings for less money instead of one large drawing would be the best incentive to encourage increased participation of current students. The gift card recommendations ranged from local eateries and gas cards, to retail stores. The option to participate in a raffle for a \$20 gift card from Wal-Mart, a local gas station or the university's book store was provided to the research study participants.

The researcher downloaded the survey results from SurveyMonkey ${ }^{\mathrm{TM}}$ directly into Statistical Package for the Social Sciences (SPSS). Through this process, SurveyMonkey ${ }^{\mathrm{TM}}$ automatically coded the Likert scale items as follows: $1=$ Strongly Agree, $2=$ Somewhat Agree, $3=$ Neither Agree nor Disagree; $4=$ Somewhat Disagree; $5=$ Strongly Disagree. To reverse the coding of the scale, the researcher imported the results from SurveyMonkey ${ }^{\mathrm{TM}}$ into an Excel spreadsheet and re-coded the survey result items as follows: $5=$ Strongly Agree, $4=$ Somewhat Agree, 3 = Neither Agree nor Disagree, 2 = Somewhat Disagree, $1=$ Strongly Disagree. Once the results were correctly coded, the information was exported to SPSS for data analysis.

Data collection. Once the survey and processes were revised, the 600 peer mentors who participated in the university's peer mentoring program received an invitation letter to participate (Appendix F), the SurveyMonkey ${ }^{\mathrm{TM}}$ cover letter (Appendix G) and the on-line survey (Appendix D) through SurveyMonkey ${ }^{\mathrm{TM}}$. Personal identification numbers (PINs) were assigned randomly to the respondents. The researcher did not have access to the PINs. The participants were given two weeks to respond. A reminder was sent after three days, a second reminder was sent on the eighth day and a final reminder was sent on the twelfth day. 
All participants were provided with an incentive to complete the survey. The incentive was determined by the pilot study. Of the 342 participants who returned the survey, 315 voluntarily participated in a raffle to win potential prizes ranging from the value of $\$ 20$ to $\$ 200$. Interested participants were asked to enter their email address to be eligible for the raffle. To ensure the confidentiality of the participants' responses, subjects' email addresses were not attached to data collection and study results. Email addresses were properly discarded immediately after winners were determined. Respondents were not required to participate in the raffle. Their names and other identifiable information were not connected to the original survey.

Survey instrument. The survey instrument consists of three sections. The first section focuses on demographic information pertaining to the peer mentors (Appendix D). The thirteen demographic questions provide self-reported information about the participants, such as credits earned, longevity of service, residential status, age, marital and parental status, ethnic background, gender, major, grade point average, and whether they were assigned a peer mentor when they started college.

The second section of the survey instrument provides statements in reference to peer mentors' perceived learning and development (Appendix D). These statements were designed based on the information within the literature review. The researcher sought to identify whether students perceive that they have gained skills in such areas as academic success, collaboration, communication skills, decision-making and problem-solving, diversity, intrinsic benefits, leadership development, reflection, and student engagement. In addition, the researcher was also seeking to identify whether peer mentors have benefitted intrinsically due to their participation in the peer mentoring program and become more engaged in their university experience. 
The final portion of the survey instrument investigates peer mentors' satisfaction with their mentoring experiences. The satisfaction portion is divided into two sections. First, participants were asked to respond to statements regarding their satisfaction with their interactions with mentoring program staff. These statements included satisfaction on the staff's friendliness, approachability, helpfulness, timeliness, and satisfaction with weekly information that is provided to peer mentors. Next, the participants were asked to respond to statements concerning their satisfaction with their mentoring experience. These statements addressed whether the peer mentors felt sufficiently prepared to serve in this role, their satisfaction with the matching process, the amount of time required to serve as a peer mentor, and their overall satisfaction with the mentoring experience.

The survey included two statements that were negatively-worded stems. These two items were added to prevent acquiescence (yea-saying). According to Suskie (2004), adding opposing views “will help to prevent the ,yeasayer/naysayer' effect, in which some people with generally positive feelings toward your topic may check all the „strongly agree' response without reading each item and those with generally negative feelings may do the opposite" (p. 228).

\section{Limitations of this Study}

1. Learning and development was measured by self-reporting of the participants; therefore the study is limited by the accuracy of the respondents' self-perceptions.

2. This study was a volunteer sample at a single institution. Therefore, the respondents of this study may not represent all peer mentors.

3. This study was conducted during the spring 2011 semester and may not represent past or future peer mentoring cohorts. 


\section{Data Analysis}

The researcher used descriptive statistics and the Statistical Package for the Social Sciences (SPSS) computer software to analyze the demographic data from the survey instrument. Percentages and frequencies are reported for each of the demographic questions.

Research Question 1: What learning and development has occurred for students who serve as university peer mentors?

Descriptive statistics were used to describe survey items that address the first research question. Percentages and frequencies were calculated for each of the survey items that addressed learning and development to illustrate the proportion of responses in each of the Likert scale levels ( $5=$ Strongly Agree, $4=$ Somewhat Agree, $3=$ Neither Agree nor Disagree, $2=$ Somewhat Disagree, 1 = Strongly Disagree). Perceived learning and development were coded into nine categories and were addressed in survey items numbered 14 through 31 and survey items numbered 33 through 41. The nine categories of Learning and Development are as follows:

1. Academic Success (Survey Items 24, 26, 28, 29, 30)

2. Collaboration (Survey Items 15,17 )

3. Communication Skills (Survey Items 20, 21, 22)

4. Decision-Making and Problem-Solving (Survey Items 16, 19, 31)

5. Diversity (Survey Items 14,18 )

6. Intrinsic Benefits (Survey Items 27, 34, 37, 38)

7. Leadership Involvement (Survey Items 35, 36)

8. Reflection (Survey Items 23, 25)

9. Student Engagement (Survey Items 33, 39, 40, 41) 


\section{Research Question 2: How satisfied are student peer mentors with (a) the mentoring} program staff and $(b)$ the mentoring program experience?

Descriptive statistics also were used to address the second research question. Percentages were calculated for each of the survey items that addressed satisfaction to illustrate the proportion of responses in each of the Likert scale levels $(5=$ Strongly Agree, $4=$ Somewhat Agree, 3 = Neither Agree nor Disagree, 2 = Somewhat Disagree, $1=$ Strongly Disagree). Satisfaction was coded into two major categories:

a) Satisfaction with the Mentoring Program Staff (Survey Items 44, 45, 47, 48)

b) Satisfaction with the Mentoring Experience (Survey Items 43, 46, 49, 50)

Research Question 3: Is there a statistically significant difference by number of years experience as peer mentor in (a) peer mentors' satisfaction with the mentoring program staff, (b) peer mentors' satisfaction with the mentoring experience, and (c) peer mentors' perceived learning and development?

For Research Question 3, a Cronbach's alpha test was administered to determine internal consistency amongst the items in this category. Ideally, Cronbach's alpha coefficient of a scale should be above a 7 (Pallant, 2007). Cronbach's alpha values are "quite sensitive to the number of items in the scale" (Pallant, 2007, p. 95). Therefore, scales with less than ten items, may have a low Cronbach's value (e.g. .5) (Pallant, 2007). In these situations, it is more appropriate to report the mean inter-item correlation. A mean inter-item correlation score below .1 is unlikely to adequately represent the complexity of the category and a score higher than .5 tends to be too specific (Briggs \& Cheek, 1986). Where permissible, either based on Cronbach's alpha or the mean inter-item correlation, the items for a scale were combined into a single item. This was accomplished in SPSS by creating a new variable using the averaged responses of the peer 
mentors. Combining items into a single item negated the necessity for a MANOVA and allowed a single ANOVA to be computed for the combined item for the section of the survey.

In Research Question 3a, the years of service (one, two, three or more) served as the independent variable. The dependent variable was satisfaction with the mentoring program staff. To determine if there was a statistically significant difference in peer mentors' satisfaction with the mentoring program staff (Research Question 3a) based on the number of years that students served as peer mentors, a Cronbach's alpha or the mean inter-item correlation value was utilized to determine if the items within the category could be combined into a single item. For example, for Satisfaction with the Mentoring Program Staff, items 44, 45, 47, and 48 were combined into a single item, Satisfaction with the Mentoring Program Staff. A one-way ANOVA was then computed.

In Research Question 3b, the years of service served as the independent variable. The dependent variable was satisfaction with the mentoring experience. To determine if there were statistically significant differences in the peer mentors' satisfaction with the mentoring experience (Research Question 3b) based on the number of years that students served as peer mentors, either a Cronbach's alpha or the mean inter-item correlation value was utilized to determine if the items for a scale could be combined into a single item. For example, for Satisfaction with the Mentoring Experience, items 43, 46, 49, and 50 were combined into a single item, Satisfaction with the Mentoring Experience. A one-way ANOVA was then computed.

For Research Question 3c, the years of service (one, two, three or more) served as the independent variable. The dependent variables were the nine categories of perceived learning and development. To determine if there were statistically significant differences in peer 
mentors' perceived learning and development (Research Question 3c) based on the number of years that students served as peer mentors, learning and development was divided into nine categories: Academic Success, Collaboration, Communication Skills, Decision-Making and Problem-Solving, Diversity, Intrinsic Benefits, Leadership Involvement, Reflection, and Student Engagement. Each of the nine categories was treated separately for statistical analysis. The items within each category were combined into a single item, and a Cronbach's alpha test and/or the mean inter-item correlation test were administered to determine internal consistency. Consistency was determined for each of the categories; therefore making it permissible to combine the survey items within each of the nine categories to yield nine items. For example, for Academic Success, items 24, 26, 28, 29, and 30 were combined into a single item, Academic Success. The nine items were treated separately for statistical analysis. A one-way ANOVA could then be computed for each item without first computing a MANOVA.

Research Question 4: Based on the peer mentors' university college (College of Education and Human Services; College of Science and Technology; College of Liberal Arts), is there a statistically significant difference in (a) satisfaction with the mentoring program staff, (b) satisfaction with the mentoring experience, and (c) peer mentors' perceived learning and development?

For Research Question 4, a Cronbach's alpha test was administered to determine internal consistency amongst the items in this category. Ideally, Cronbach's alpha coefficient of a scale should be above a .7 (Pallant, 2007). Cronbach's alpha values are “quite sensitive to the number of items in the scale" (Pallant, 2007, p. 95). Therefore, scales with less than ten items, may have a low Cronbach's value (e.g. .5) (Pallant, 2007). In these situations, it is more appropriate to report the mean inter-item correlation. A mean inter-item correlation score below .1 is unlikely 
to adequately represent the complexity of the category and a score higher than .5 tends to be too specific (Briggs \& Cheek, 1986). Where permissible, either based on Cronbach's alpha or the mean inter-item correlation, the items for a scale were combined into a single item. This was accomplished in SPSS by creating a new variable using the averaged responses of the peer mentors. Combining items into a single item negated the necessity for a MANOVA and allowed a single ANOVA to be computed for the combined item for the section of the survey.

In Research Question 4a, the peer mentors' university college (College of Education and Human Services, College of Science, and Technology, and College of Liberal Arts) served as the independent variable. The dependent variable was satisfaction with the mentoring program staff. To determine if there was a statistically significant difference in peer mentors' satisfaction with the mentoring program staff (Research Question 4a) based on the peer mentors' university college, either a Cronbach's alpha or the mean inter-item correlation value was utilized to determine if the items for the scale could be combined into a single item. For example, for Satisfaction with the Mentoring Program Staff, items 44, 45, 47, and 48 were combined into a single item, Satisfaction with the Mentoring Program Staff. A one-way ANOVA was computed. In Research Question 4b, the peer mentors' university college served as the independent variable. The dependent variable was satisfaction with the mentoring experience. To determine if there were statistically significant differences in peer mentors' satisfaction with the mentoring experience (Research Question 4b) based on the peer mentors' university college, either a Cronbach's alpha or the mean inter-item correlation value was utilized to determine if the items for the scale could be combined into a single item. For example, for Satisfaction with the Mentoring Experience, items 43, 46, 49, and 50 were combined into a single item, Satisfaction with the Mentoring Experience. A one-way ANOVA was then computed. 
For Research Question 4c, the peer mentors' university college served as the independent variable. The dependent variables were the nine categories of perceived learning and development. To determine if there were statistically significant differences in peer mentors' perceived learning and development (Research Question 4c) based on the peer mentor's university college, learning and development was divided into nine categories: Academic Success, Collaboration, Communication Skills, Decision-Making and Problem-Solving, Diversity, Intrinsic Benefits, Leadership Involvement, Reflection, and Student Engagement. A Cronbach's alpha test and/or the mean inter-item correlation test were administered to determine internal consistency for each of the nine categories. Consistency was determined for each of the categories; therefore making it permissible to combine the survey items within each of the nine categories to yield nine items. To illustrate, for Academic Success, items 24, 26, 28, 29, and 30 were combined into a single item, Academic Success. The nine items were treated separately for statistical analysis. A one-way ANOVA was then computed.

Research questions with corresponding survey items. The study's four research questions are shown in Table 1 with the corresponding survey items. Also, the survey items are coded in Appendix D for review, but are not be coded in the actual survey administered to the peer mentors. 
Table 1

Research Questions with Corresponding Survey Items

\begin{tabular}{|c|c|}
\hline Research Question & Corresponding Survey Items \\
\hline $\begin{array}{l}\text { 1. What learning and development has occurred for } \\
\text { students who serve as university peer mentors? }\end{array}$ & $\begin{array}{l}\text { - Learning and Development: } \\
\text { Items } 14 \text { to } 31 \& 33 \text { to } 41\end{array}$ \\
\hline $\begin{array}{l}\text { 2. a. How satisfied are student peer mentors with the } \\
\text { mentoring program staff? }\end{array}$ & $\begin{array}{l}\text { - Satisfaction: Items } 44,45 \text {, } \\
47,48\end{array}$ \\
\hline $\begin{array}{l}\text { b. How satisfied are student peer mentors with } \\
\text { the mentoring experience? }\end{array}$ & $\begin{array}{l}\text { - Satisfaction: Items } 43,46 \text {, } \\
49,50\end{array}$ \\
\hline $\begin{array}{l}\text { 3. a. Is there a statistically significant difference by } \\
\text { number of years experience as peer mentor in } \\
\text { peer mentors' satisfaction with the mentoring } \\
\text { program staff? }\end{array}$ & $\begin{array}{l}\text { - Years of Experience: Item } 2 \\
\text { - Satisfaction with Mentoring } \\
\text { Program Staff: Items 44, 45, } \\
\text { 47, } 48\end{array}$ \\
\hline $\begin{array}{l}\text { b. Is there a statistically significant difference by } \\
\text { number of years experience as peer mentor in } \\
\text { peer mentors' satisfaction with the mentoring } \\
\text { experience? }\end{array}$ & $\begin{array}{l}\text { - Years of Experience: Item } 2 \\
\text { - Satisfaction with Mentoring } \\
\text { Experience: Items } 43,46,49 \text {, } \\
50\end{array}$ \\
\hline $\begin{array}{l}\text { c. Is there a statistically significant difference by } \\
\text { number of years experience of peer mentor in } \\
\text { peer mentors' perceived learning and } \\
\text { development? }\end{array}$ & $\begin{array}{l}\text { Years of Experience: Item } 2 \\
\text { Learning and Development: } \\
\text { Items } 14 \text { to } 31 \& 33 \text { to } 41\end{array}$ \\
\hline $\begin{array}{l}\text { 4. a. Based on the peer mentors' university college } \\
\text { (College of Education and Human Services; } \\
\text { College of Science and Technology; College of } \\
\text { Liberal Arts), is there a statistically significant } \\
\text { difference in satisfaction with the mentoring } \\
\text { program staff? }\end{array}$ & $\begin{array}{l}\text { - University College: Item } 11 \\
\text { - Satisfaction with Mentoring } \\
\text { Program Staff: Items } 44,45 \text {, } \\
47,48\end{array}$ \\
\hline
\end{tabular}


Table 1 Research Questions with Corresponding Survey Items (continued)

b. Based on the peer mentors' university college (College of Education and Human Services; College of Science and Technology; College of Liberal Arts), is there a statistically significant difference in satisfaction mentoring experience?

c. Based on the peer mentors' university college (College of Education and Human Services; College of Science and Technology; College of Liberal Arts), is there a statistically significant difference in peer mentors' perceived learning and development?
- University College: Item 11

- Satisfaction with Mentoring Experience: Items 43, 46, 49 50

- University College: Item 11

- Perceived Learning and Development: Items 14 to $31 \& 33$ to 41

\section{Summary}

This chapter described the research design used to address the four research questions identified in Chapter one. The researcher presented information that described the selected site, the sampling procedure, the data collection and survey instrument, and the data analysis. The pilot study results were reviewed and a list of limitations of this study was also provided within this chapter. In Chapter Four, the researcher will report the major findings of this study. In the final chapter, the researcher will provide a summary of the study, conclusions, and recommendations for future studies. 


\section{Chapter Four}

\section{Results}

This dissertation study examined university peer mentors' perceived student learning and development. In addition, this study also examined peer mentors' satisfaction levels with the peer mentoring program and their peer mentoring experiences based on the college in which their major is housed (university college) and the number of years they served as a peer mentors.

The results of this investigation are reported in accordance with the four research questions. Research Question 1 concerns the learning and development of peer mentors. Research Question 2 examines peer mentors' satisfaction with their participation in the peer mentoring program. Research Question 3 explores whether significant differences exist in peer mentors' satisfaction and perceived learning and development based on the number of years they served as peer mentors. Research Question 4 examines whether significant differences exist in peer mentors' satisfaction and perceived learning and development based on the college in which their major is housed (university college).

\section{Peer Mentor Survey Responses}

The population for this study was the 600 student peer mentors at Hillview State University (fictitious) who served as peer mentors during the Fall 2010 and Spring 2011 Semesters. A total of 342 surveys were returned and the final number of completed surveys that were used for this study and analyzed was 317 , which represented a 52.8 percent response rate.

There were 19 incomplete surveys, with less than $50 \%$ of the survey completed. These respondents' surveys were not used in this dissertation study. The survey also included two statements that had opposing views. The first survey item was number 32, which states "I prefer working alone when making decisions and solving problems" is in opposition of the two survey 
items (survey items 15 and 17) which support working collaboratively. The second survey item was number 42 which states "I feel that my involvement in the peer mentoring program has had NO effect on my learning and development," which is in opposition of the learning and development portion of the survey. According to Suskie (2004), adding opposing views "will help to prevent the ,yeasayer/naysayer' effect," (p. 228) in which some people select all "strongly agree" responses or all "strongly disagree" responses. Six survey participants responded with all $5 \mathrm{~s}$ or $4 \mathrm{~s}$, which displayed signs of "yeasayers" by selecting all of the same response throughout the survey rather than carefully reading each item. These participants' responses were not included in the sample.

\section{Demographic Information of Study Participants}

Peer mentors were asked 13 demographic questions. Of the 317 respondents, $81.4 \%$ of them were assigned a peer mentor during their first year at HSU. Eighty-nine percent of the peer mentors started HSU as freshmen; eleven percent started the university as transfer students. As shown in Table 2, 38.5\% of the respondents reported being seniors (90+ credits completed), $34.7 \%$ reported being juniors (60-89 credits completed), and $26.8 \%$ reported being sophomores (30-59 credits completed).

Table 2

HSU Peer Mentors' Class Rank

$\mathrm{N} \%$

Sophomores (30-59 credits completed) 85 26.8

Juniors (60-89 credits completed) 110 34.7

Seniors $(90+$ credits completed) 122 38.5

Total 
A total of 310 peer mentors reported their cumulative grade point average (gpa) at HSU. The mean gpa was 3.45 , with a range of 1.66 . The minimum score was 2.34 , and the maximum score was 4.00. One respondent provided 3.25-3.5 as his gpa. The researcher changed the response to a central number of 3.38 .

Respondents were asked to identify their ethnicity. The majority of the peer mentors self-identified White/Caucasian/European American (91.5\%). The second highest response was African-American/Black (4.4\%). The remaining 4.1\% was distributed amongst the other ethnic identifications (see Table 3).

Table 3

HSU Peer Mentors by Ethnic Identification

\begin{tabular}{lcc}
\hline & $\mathrm{N}$ & $\%$ \\
White/Caucasian/European American & 290 & 91.5 \\
African-American/Black & 14 & 4.4 \\
Hispanic-American/Latino/Chicano & 4 & 1.3 \\
Multi-Racial & 3 & .9 \\
Other, don't know or prefer not to answer & 6 & 1.9 \\
Total & 317 & \\
\hline
\end{tabular}

The majority of the peer mentors lived on or near campus, with $44.3 \%$ of peer mentors living in on-campus and off-campus HSU housing and 37.7\% living within 5 miles of HSU's campus. Only $18 \%$ of HSU's peer mentors reported living more than 5 miles from HSU's campus (see Table 4), with $16.4 \%$ of the peer mentors living with their parents (see Table 5). 
Table 4

HSU Peer Mentor Residential Status

\section{$\mathrm{N}$}

79

HSU On-Campus Housing

HSU's Off-Campus Housing

Housing within 5 Miles of Campus

Housing more than 5 Miles of Campus

No Responses

Total
61

19.3

119

37.7

57

18.0

1

317

Table 5

HSU Peer Mentors who Live with Their Parents

$\mathrm{N} \%$

Lived with their parents

52

16.4

Did not live with their parents

265

83.6

317

The majority of peer mentors were 22 years old or younger with $52.4 \%$ between 21 to 22 years old, and $39.7 \%$ were 18 to 20 years old. The remaining peer mentors were 23 years or older (7.9\%) (see Table 6). Although the majority of students in this particular peer mentoring program were under the age of 25 , some of these students may classify themselves as nontraditional due to family obligations, such as children and work. The National Center for Education Statistics (2002) utilizes age, plus other criteria, to identify a student as nontraditional. Enrollment patterns, financial, and family status and high school graduation status 
are also taken into consideration when categorizing non-traditional students. For this study, participants were asked their age, marital status, and whether they had children, to determine non-traditional status. A small percentage of the HSU peer mentors met the criteria for nontraditional status. Table 6 illustrates that $2.5 \%$ of the peer mentors were 25 years or older. The majority (98.7\%) of the peer mentors were single (see Table 7) and never had children (98.7\%) (see Table 8).

Table 6

HSU Peer Mentors' Age

\begin{tabular}{lcc}
\hline & $\mathrm{N}$ & $\%$ \\
18 to 20 years & 126 & 39.7 \\
21 to 22 years & 166 & 52.4 \\
23 to 24 years & 17 & 5.4 \\
25 to 26 years & 1 & .3 \\
27 years or older & 7 & 2.2 \\
Total & 317 & \\
\hline
\end{tabular}


Table 7

HSU Peer Mentors' Marital Status

$\mathrm{N} \%$

Single, Never Married

312

98.7

Married

3

.9

Divorced

1

.3

No Responses

1

Total

Table 8

HSU Peer Mentors with Children

$\mathrm{N} \quad \%$

Peer Mentors without Children

312

98.7

Peer Mentors with Children

4

1.3

No Responses

1

Total

317

Respondents served as peer mentors for one to three years or more. As shown in Table 9, $52.1 \%$ of the total respondents served one year as a mentor; $30 \%$ of the total respondents served two years as a mentor; and $18 \%$ of the total respondents served three or more years as a mentor. These numbers closely represent the total HSU peer mentor population in which $55.5 \%$ were one-year mentors, $28.1 \%$ were two-year mentors and $16.3 \%$ represented mentors who served three or more years. 
Table 9

Number of Years HSU Peer Mentors Served as Peer Mentors

$\mathrm{N} \%$

One Year

165

52.1

Two Years

95

30.0

Three Years or More

18.0

Total

317

Respondents were enrolled in three different colleges. More than half $(53.5 \%)$ of the peer mentors were from College of Education and Human Services. The remaining half was divided nearly evenly between the College of Science and Technology (24.1\%) and the College of Liberal Arts (22.5\%) (see Table 10). The distribution of the respondents based on college is very similar to the total HSU peer mentor population with $49.3 \%$ from the College of Education and Human Services, $28.1 \%$ from the College of Science and Technology, and $22.5 \%$ from the College of Liberal Arts.

Table 10

College Breakdown of HSU Peer Mentors

$\mathrm{N} \quad \%$

College of Education and Human Service

169

53.5

College of Science and Technology

76

24.1

College of Liberal Arts

71

22.5

Total 


\section{Results for Each Research Question}

Research Question 1: What learning and development has occurred for students who serve as university peer mentors? For each survey item, the frequencies (f) and percentages (\%) of levels of agreement are calculated. In addition, the means are shown for the individual survey items (SI).

Collaboration. As noted in Table 11, the majority (88\%) of peer mentors reported that they collaborate with colleagues and peers. The majority $(92.4 \%)$ of these students also reported that they value working cooperatively (see Table 11).

Communication Skills. At least three-quarters of the peer mentors either strongly agreed or somewhat agreed that they have enhanced their listening skills, their interpersonal communication skills and their confidence in public speaking (see Table 11).

Decision-Making and Problem-Solving. Ninety-five percent of the peer mentors at least somewhat agreed that they assisted their protégés with decision-making and problem-solving. Eighty percent at least somewhat agreed they improved their own personal decision-making and problem-solving. Nearly three quarters $(72.4 \%)$ reported they either strongly agreed or somewhat agreed they assisted protégés with setting goals (see Table 11). 
Table 11

Summary of Collaboration, Communication Skills, and Decision-Making \& Problem-Solving

Categories and Survey Items

$\begin{array}{lllll} & & & & \\ & & & & \\ & & \mathrm{f} & \%\end{array}$

Levels of Agreement

\section{Collaboration}

SI 15 Collaborate with Colleagues and Peers $(\mathrm{N}=317)$

$\begin{array}{llll}171 & 53.9 & 108 & 34.1\end{array}$

$\begin{array}{ccccccc} & & & & & & \\ \text { f } & \% & \text { f } & \% & \text { f } & \%\end{array}$

SI 17 Value Working Cooperatively $(\mathrm{N}=315)$

$\begin{array}{llrr}200 & 63.5 & 91 & 28.9\end{array}$

$\begin{array}{ll}30 & 9.5 \\ 17 & 5.4\end{array}$

$\begin{array}{rrrrrrrrrrr}198 & 62.7 & 95 & 30.1 & 22 & 7.0 & 1 & 0.3 & 0 & 0.0 & 4.55 \\ 157 & 50.0 & 125 & 39.8 & 31 & 9.9 & 0 & 0.0 & 1 & 0.3 & 4.39 \\ 133 & 42.2 & 111 & 35.2 & 58 & 18.4 & 6 & 1.9 & 7 & 2.2 & 4.13\end{array}$

Decision-Making (DM) and Problem-Solving (PS)

SI 16 Assisted Protégé with Setting Goals $(\mathrm{N}=315)$

SI 19 Assisted Protégé DM and PS Decision ( $\mathrm{N}=316)$

SI 31 Improved Personal DM and PS (N=310)

$\begin{array}{rrrrrrrrrrr}98 & 31.1 & 130 & 41.3 & 59 & 18.7 & 19 & 6.0 & 9 & 2.9 & 3.92 \\ 156 & 49.4 & 144 & 45.6 & 16 & 5.1 & 0 & 0.0 & 0 & 0.0 & 4.44 \\ 117 & 37.7 & 132 & 42.6 & 57 & 18.4 & 3 & 1.0 & 1 & 0.3 & 4.16\end{array}$

Notes: 5 = Strongly Agree, $4=$ Somewhat Agree, $3=$ Neither Agree nor Disagree, $2=$ Somewhat Disagree, $1=$ Strongly Disagree 
Academic Success. As noted in Table 12, the majority (87.6\%) of peer mentors are more aware of the university resources. By contrast, nearly one-third of these peer mentors reported they were neutral or somewhat disagreed that they utilized university resources.

Intrinsic Benefits. Across the four items comprising intrinsic benefits, at least eighty percent of the peer mentors either strongly or somewhat agreed that they achieved the following: increased self-confidence, increased confidence in personal problem-solving abilities, and enhanced confidence in ability to lead others. The peer mentors also believed that their involvement in the mentoring program has enhanced their college experience (see Table 12).

Reflection. A majority (83\%) of peer mentors perceived that they are more aware of how they learn and study. In a similar manner, the majority $(87.6 \%)$ of students also reported in Academic Success that they have adapted their study skills to become academically successful. Peer mentors $(90.8 \%)$ indicated that they are more aware of their skills and abilities, such as communication skills, time management skills and organizational skills (see Table 12). 
Table 12

Summary of Academic Success, Intrinsic Benefits, and Reflection

\begin{tabular}{|c|c|c|c|c|c|c|c|c|c|c|c|}
\hline \multirow{3}{*}{ Categories and Survey Items } & \multicolumn{11}{|c|}{ Levels of Agreement } \\
\hline & \multicolumn{2}{|c|}{5} & \multicolumn{2}{|c|}{4} & \multicolumn{2}{|c|}{3} & \multicolumn{2}{|c|}{2} & \multicolumn{2}{|c|}{1} & \multirow[t]{2}{*}{ M } \\
\hline & $\mathrm{f}$ & $\%$ & $\mathrm{f}$ & $\%$ & $\mathrm{f}$ & $\%$ & $\mathrm{f}$ & $\%$ & $\mathrm{f}$ & $\%$ & \\
\hline \multicolumn{12}{|l|}{ Academic Success } \\
\hline SI 24 Adapted Study Skill (N=314) & 149 & 47.5 & 126 & 40.1 & 31 & 9.9 & 5 & 1.6 & 3 & 1.0 & 4.32 \\
\hline SI 26 Time Mgt \& Organizational Skills $(\mathrm{N}=316)$ & 151 & 47.8 & 117 & 37.0 & 39 & 12.3 & 8 & 2.5 & 1 & 0.3 & 4.29 \\
\hline SI 28 Awareness of University Resources $(\mathrm{N}=314)$ & 193 & 61.5 & 82 & 26.1 & 33 & 10.5 & 5 & 1.6 & 1 & 0.3 & 4.47 \\
\hline SI 29 Utilized University Resources $(\mathrm{N}=315)$ & 125 & 39.7 & 86 & 27.3 & 60 & 19.0 & 34 & 10.8 & 10 & 3.2 & 3.90 \\
\hline SI 30 GPA Increased $(\mathrm{N}=314)$ & 89 & 28.3 & 98 & 31.2 & 103 & 32.8 & 20 & 6.4 & 4 & 1.3 & 3.79 \\
\hline \multicolumn{12}{|l|}{ Intrinsic Benefits } \\
\hline SI 27 Peer Mentoring Enhanced Experience $(\mathrm{N}=315)$ & 167 & 53.0 & 103 & 32.7 & 40 & 12.7 & 3 & 1.0 & 2 & 0.6 & 4.37 \\
\hline SI 34 Confident in Abilities to Lead Others $(\mathrm{N}=316)$ & 146 & 46.2 & 141 & 44.6 & 27 & 8.5 & 1 & 0.3 & 1 & 0.3 & 4.36 \\
\hline SI 37 Self-Confidence has Increased $(\mathrm{N}=316)$ & 125 & 39.6 & 127 & 40.2 & 56 & 17.7 & 6 & 1.9 & 2 & 0.6 & 4.16 \\
\hline SI 38 Confident in Abilities to Solve Problems $(\mathrm{N}=313)$ & 128 & 40.9 & 137 & 43.8 & 43 & 13.7 & 3 & 1.0 & 2 & 0.6 & 4.23 \\
\hline \multicolumn{12}{|l|}{ Reflection } \\
\hline SI 23 Awareness of Learning \& Studying $(\mathrm{N}=316)$ & 149 & 47.2 & 113 & 35.8 & 43 & 13.6 & 8 & 2.5 & 3 & 0.9 & 4.26 \\
\hline SI 25 Awareness of Skills \& Abilities $(\mathrm{N}=315)$ & 179 & 56.8 & 107 & 34.0 & 26 & 8.3 & 2 & 0.6 & 1 & 0.3 & 4.46 \\
\hline
\end{tabular}

Notes: $5=$ Strongly Agree, $4=$ Somewhat Agree, $3=$ Neither Agree nor Disagree, $2=$ Somewhat Disagree, $1=$ Strongly Disagree 
Student Engagement. A majority (85.4\%) of the peer mentors strongly or somewhat agreed that they know more students in their major and are comfortable interacting with their professors $(84.4 \%)$. By contrast, one-third of the peer mentors were neutral or disagreed that they participated in campus activities more often. Another one-third was neutral or disagreed that they were more comfortable asking questions in class (see Table 13).

Leadership Involvement. Peer mentors reported less participation in leadership roles or development opportunities than might be expected at the undergraduate level. Nearly $40 \%$ of the students either were neutral or disagreed that they participated in leadership development opportunities (such as leadership courses and/or workshops). Over one-third were neutral or disagreed that have held one leadership position in a student organization (see Table 13).

Diversity. Nearly ninety-six percent of the peer mentors feel that they have had the opportunity to meet and work with people who are different from themselves. The majority (94.3\%) of peer mentors also strongly or somewhat agreed that they understand the difference in their protégés and adapt their mentoring approach accordingly (see Table 13). 
Peer Mentors' Learning and Development 57

Table 13

Summary of Student Engagement, Leadership Involvement, and Diversity

\begin{tabular}{|c|c|c|c|c|c|c|c|c|c|c|c|}
\hline \multirow{3}{*}{ Categories and Survey Items } & \multicolumn{10}{|c|}{ Levels of Agreement } & \multirow{3}{*}{ M } \\
\hline & \multicolumn{2}{|c|}{5} & \multicolumn{2}{|c|}{4} & \multicolumn{2}{|c|}{3} & \multicolumn{2}{|c|}{2} & \multicolumn{2}{|c|}{1} & \\
\hline & $\mathrm{f}$ & $\%$ & $\mathrm{f}$ & $\%$ & $\mathrm{f}$ & $\%$ & $\mathrm{f}$ & $\%$ & $\mathrm{f}$ & $\%$ & \\
\hline \multicolumn{12}{|l|}{ Student Engagement } \\
\hline SI 33 Increased Campus Participation $(\mathrm{N}=315)$ & 107 & 34.0 & 117 & 37.1 & 63 & 20.0 & 23 & 7.3 & 5 & 1.6 & 3.95 \\
\hline SI 39 Know More Students in Major $(\mathrm{N}=315)$ & 194 & 61.6 & 75 & 23.8 & 38 & 12.1 & 5 & 1.6 & 3 & 1.0 & 4.43 \\
\hline SI 40 Comfortable Interacting with Professors $(\mathrm{N}=313)$ & 179 & 57.2 & 85 & 27.2 & 45 & 14.4 & 2 & 0.6 & 2 & 0.6 & 4.40 \\
\hline SI 41 Comfortable Asking Questions in Class $(\mathrm{N}=313)$ & 128 & 40.9 & 94 & 30.0 & 67 & 21.4 & 17 & 5.4 & 7 & 2.2 & 4.02 \\
\hline \multicolumn{12}{|l|}{ Leadership Involvement } \\
\hline SI 35 Leadership in Student Organization $(\mathrm{N}=313)$ & 152 & 48.6 & 40 & 12.8 & 58 & 18.5 & 27 & 8.6 & 36 & 11.5 & 3.78 \\
\hline SI 36 Leadership Development Opportunities $(\mathrm{N}=315)$ & 99 & 31.4 & 102 & 32.4 & 71 & 22.5 & 28 & 8.9 & 15 & 4.8 & 3.77 \\
\hline \multicolumn{12}{|l|}{ Diversity } \\
\hline SI 14 Understand Differences $(\mathrm{N}=317)$ & 197 & 62.1 & 102 & 32.2 & 16 & 5.0 & 1 & 0.3 & 1 & 0.3 & 4.56 \\
\hline SI 18 Opportunity to Meet Others $(\mathrm{N}=316)$ & 227 & 71.8 & 76 & 24.1 & 10 & 3.2 & 2 & 0.6 & 1 & 0.3 & 4.66 \\
\hline
\end{tabular}

Notes: 5 = Strongly Agree, $4=$ Somewhat Agree, $3=$ Neither Agree nor Disagree, $2=$ Somewhat Disagree, $1=$ Strongly Disagree 
Research Question 2: How satisfied are student peer mentors with (a) the mentoring program staff and $(b)$ the mentoring program experience? For Research Question 2, satisfaction was coded into two categories: Satisfaction with the Mentoring Program Staff and Satisfaction with the Mentoring Experience. These categories are illustrated in Table 14 with the corresponding survey items. For each survey item, the frequencies and percentages of levels of agreement are calculated. The means are shown for the individual items.

Satisfaction with the Mentoring Program Staff. As noted in Table 14, over 90\% of the peer mentors strongly or somewhat agreed that the mentoring program staff was friendly, approachable, and helpful. Over, $85 \%$ of the peer mentors also strongly or somewhat agreed that they were satisfied with the weekly information provided by the mentoring program staff and felt the mentoring program staff responds in a timely manner.

Satisfaction with the Mentoring Experience. Approximately $90 \%$ of the peer mentors felt that they were prepared to serve as mentors and were satisfied with the time required to serve as a peer mentor. Nearly $93 \%$ of the peer mentors indicated that they were satisfied with the mentoring experience. However, by contrast, over $25 \%$ of the peer mentors were neutral or not satisfied with their protégé match (see Table 14). 
Peer Mentors' Learning and Development 59

Table 14

Summary of Peer Mentors' Satisfaction

\begin{tabular}{|c|c|c|c|c|c|c|c|c|c|c|c|}
\hline & & & & & ls of & Agree & & & & & \\
\hline & & 5 & & + & & 3 & & 2 & & 1 & M \\
\hline & $\mathrm{f}$ & $\%$ & $\mathrm{f}$ & $\%$ & $\mathrm{f}$ & $\%$ & $\mathrm{f}$ & $\%$ & $\mathrm{f}$ & $\%$ & \\
\hline Satisfaction with Mentoring Program Staff & & & & & & & & & & & \\
\hline SI 44 Friendly and Approachable (N=314) & 240 & 76.4 & 55 & 17.5 & 18 & 5.7 & 0 & 0.0 & 1 & 0.3 & 4.70 \\
\hline SI 45 Satisfied with Weekly Information (N=312) & 184 & 59.0 & 88 & 28.2 & 31 & 9.9 & 5 & 1.6 & 4 & 1.3 & 4.42 \\
\hline SI 47 Mentoring Staff is Helpful $(\mathrm{N}=315)$ & 214 & 67.9 & 78 & 24.8 & 22 & 7.0 & 0 & 0.0 & 1 & 0.3 & 4.60 \\
\hline SI 48 Mentoring Staff Responds Timely (N=313) & 213 & 68.1 & 57 & 18.2 & 41 & 13.1 & 1 & 0.3 & 1 & 0.3 & 4.53 \\
\hline Satisfaction with Mentoring Experience & & & & & & & & & & & \\
\hline SI 43 Training Prepared for Mentor Role $(\mathrm{N}=313)$ & 156 & 49.8 & 125 & 39.9 & 21 & 6.7 & 8 & 2.6 & 3 & 1.0 & 4.35 \\
\hline SI 46 Satisfied with Protégé Match (N=314) & 139 & 44.3 & 93 & 29.6 & 31 & 9.9 & 38 & 12.1 & 13 & 4.1 & 3.98 \\
\hline SI 49 Satisfied with Time to Serve as Mentor $(\mathrm{N}=313)$ & 223 & 71.2 & 78 & 24.9 & 12 & 3.8 & 0 & 0.0 & 0 & 0.0 & 4.67 \\
\hline SI 50 Satisfied with Mentoring Experience $(\mathrm{N}=314)$ & 217 & 69.1 & 74 & 23.6 & 13 & 4.1 & 8 & 2.5 & 2 & 0.6 & 4.58 \\
\hline
\end{tabular}

Notes: $5=$ Strongly Agree, $4=$ Somewhat Agree, $3=$ Neither Agree nor Disagree, $2=$ Somewhat Disagree, $1=$ Strongly Disagree 
Research Question 3: Is there a statistically significant difference by number of years experience as peer mentor in (a) peer mentors' satisfaction with the mentoring program staff and (b) peer mentors' satisfaction with the mentoring experience and (c) peer mentors' perceived learning and development?

For Research Question 3, a Cronbach's alpha test was administered to determine internal consistency amongst the items in that category. When the Cronbach's alpha was below the acceptable alpha coefficient of .7, the mean inter-item correlation was reported. Where permissible, either based on Cronbach's alpha or the mean inter-item correlation, the items for a scale were combined into a single item. Combining items into a single item negated the necessity for a MANOVA and allowed a single ANOVA to be computed for the combined item for the section of the survey. For example, for Satisfaction with the Mentoring Program Staff, items 44, 45, 47, and 48 were combined into a single item, Satisfaction with the Mentoring Program Staff.

Satisfaction. To determine if there was a statistically significant difference in peer mentors' satisfaction, based on the peer mentors' years of service (one, two, three or more), satisfaction was divided into two categories: Satisfaction with Mentoring Program Staff and Satisfaction with Mentoring Experience. Each of these two categories was treated separately for statistical analysis. The two categories of satisfaction constituted the dependent variable. The college in which the students' major was housed represented the independent variable.

Satisfaction with Mentoring Program Staff, Based on Number of Years. To determine if there were statistically significant differences for Research Question 3a, the Cronbach's Alpha test was administered to determine reliability of the overall category of 
Satisfaction with the Mentoring Program Staff (Survey Items 44, 45, 47, 48). Reliability was acceptable for this category $(a=.802)$. Therefore, it was permissible to collapse items 44, 45, 47, and 48 into a single combined item. An Analysis of Variance (ANOVA) test was conducted with the combined survey items. As illustrated in Table 15, the ANOVA did not yield a statistically significant finding $(d f=2,306, F=.305, p=.737)$.

Table 15

Satisfaction with Mentoring Program Staff, by Years

\begin{tabular}{lrrc}
\hline Groups* & $\mathrm{N}$ & Mean & SD \\
One Year & 159 & 4.54 & 0.605 \\
Two Years & 93 & 4.59 & 0.510 \\
Three Years & 57 & 4.59 & 0.554 \\
& & & \\
\hline *df=2, 306, $F=.305, p=.737$ & &
\end{tabular}

Satisfaction with Mentoring Experience, Based on Numbers of Years. To determine if there were statistically significant differences for Research Question 3b, a Cronbach's Alpha test was administered to determine reliability of the overall category of Satisfaction with the Mentoring Experience (Survey Items 43, 46, 49, 50). The alpha coefficient was less than the recommended score of .7 $(a=.646)$. Therefore, a mean interitem correlation was conducted and produced a score of .351 , which is within the acceptable level of homogeneity for this category. Therefore, it was permissible to collapse items 43, 46, 49 and 50 into a single item. An Analysis of Variance (ANOVA) test was conducted with the combined Satisfaction with Mentoring Experience items. As illustrated in Table 16 , the ANOVA did not yield a statistically significant finding $(d f=2$, $307, F=.492, p=.612)$. 
Table 16

Satisfaction with Mentoring Experience, by Years

\begin{tabular}{lccc}
\hline Groups* & $\mathrm{N}$ & Mean & SD \\
One Year & 160 & 4.42 & 0.597 \\
Two Years & 93 & 4.39 & 0.588 \\
Three Years & 57 & 4.33 & 0.583
\end{tabular}

$* d f=2,307, F=.492, p=.612$

Perceived Learning and Development, Based on Number of Years. To determine if there was a statistically significant difference in peer mentors' perceived learning and development by number of years experience as peer mentor, learning and development was divided into nine categories. These nine categories are: Academic Success, Collaboration, Communication Skills, Decision-Making and Problem-Solving, Diversity, Intrinsic Benefits, Leadership Involvement, Reflection, and Student Engagement, each of which was treated separately for statistical analysis. Each of these nine categories constituted the dependent variable. The number of years the students served as peer mentors represented the independent variable.

Academic Success. To determine if there were statistically significant differences in the category of Academic Success, a Cronbach's alpha test was administered to determine reliability of this category (Survey Items 24, 26, 28, 29, 30). The alpha coefficient was less than the recommended score of .7 $(a=.699)$. Therefore, a mean interitem correlation was conducted and produced a score of .333 , which is within the acceptable level of homogeneity for this category. Thus, it was permissible to collapse items 24, 26, 28, 29, and 30 into a single item. An Analysis of Variance (ANOVA) test was conducted with the combined Academic Success items (see Table 17). As illustrated 
in Table 17, the ANOVA did not yield a statistically significant finding $(d f=2,306$, $F=1.627, p=.198)$.

Table 17

Academic Success, by Years

$\begin{array}{lrcc}\text { Groups* } & \mathrm{N} & \text { Mean } & \text { SD } \\ \text { One Year } & 160 & 4.14 & 0.634 \\ \text { Two Years } & 93 & 4.22 & 0.558 \\ \text { Three Years } & 56 & 4.04 & 0.630\end{array}$

$* d f=2,306, F=1.627, p=.198$

Collaboration. To determine if there were statistically significant differences in the category of Collaboration, a Cronbach's Alpha test was administered to determine reliability of the category (Survey Items 15,17 ). The alpha coefficient was less than the recommended score of .7 $(a=.421)$. Therefore, a mean inter-item correlation was conducted and produced a score of .268 , which is within the acceptable level of homogeneity for this category. Thus, it was permissible to collapse items 15 and 17 into a single item. An Analysis of Variance (ANOVA) test was conducted with the combined Collaboration items. As illustrated in Table 18, the ANOVA did not yield a statistically significant finding $(d f=2,312, F=.946, p=.389)$.

Table 18

Collaboration, by Years

\begin{tabular}{lrrc}
\hline Groups* & $\mathrm{N}$ & Mean & SD \\
One Year & 164 & 4.45 & 0.641 \\
Two Years & 94 & 4.41 & 0.594 \\
Three Years & 57 & 4.55 & 0.488 \\
& & & \\
\hline
\end{tabular}

$* d f=2,312, F=.946, p=.389$

Communication Skills. To determine if there were statistically significant differences in the category of Communication Skills, a Cronbach's Alpha test was 
administered to determine reliability of the category (Survey Items 20, 21, 22). The alpha coefficient was less than the recommended score of .7 $(a=.692)$. Therefore, a mean inter-item correlation was conducted and produced a score of .451 , which is within the acceptable level of homogeneity for this category. Thus, it was permissible to collapse items 20, 21 and 22 into a single item. An Analysis of Variance (ANOVA) test was conducted with the combined Communication Skills items. As illustrated in Table 19, the ANOVA did not yield a statistically significant finding $(d f=2,310, F=.125, p=.883)$.

Table 19

\section{Communication Skills, by Years}

\begin{tabular}{lrrc}
\hline Groups* & $\mathrm{N}$ & Mean & SD \\
One Year & 162 & 4.35 & 0.644 \\
Two Years & 94 & 4.36 & 0.552 \\
Three Years & 57 & 4.39 & 0.557 \\
& & & \\
\hline
\end{tabular}

$* d f=2,310, F=.125, p=.883$

Decision-Making and Problem-Solving. To determine if there were statistically significant differences in the category of Decision-Making and Problem-Solving, a Cronbach's Alpha test was administered to determine reliability of the category (Survey Items 16, 19, 31). The alpha coefficient was less than the recommended score of .7 $(a=.541)$. Therefore, a mean inter-item correlation was conducted and produced a score of .296, which is within the acceptable level of homogeneity for this category. Thus, it was permissible to collapse items 16, 19, and 31 into a single item. An Analysis of Variance (ANOVA) test was conducted with the combined Decision-Making and Problem-Solving. As illustrated in Table 20, the ANOVA did not yield a statistically significant finding $(d f=2,304, F=.184, p=.832)$. 
Table 20

Decision-Making \& Problem-Solving, by Years

\begin{tabular}{lrcc}
\hline Groups* & $\mathrm{N}$ & Mean & SD \\
One Year & 159 & 4.18 & 0.599 \\
Two Years & 91 & 4.21 & 0.564 \\
Three Years & 57 & 4.15 & 0.564
\end{tabular}

$* d f=2,304, F=.184, p=.832$

Diversity. To determine if there were statistically significant differences in the category of Diversity, a Cronbach's Alpha test was administered to determine reliability of the category (Survey Items 14, 18). The alpha coefficient was less than the recommended score of $.7(a=.315)$. Therefore, a mean inter-item correlation was conducted and produced a score of .188, which is within the acceptable level of homogeneity for this category. Thus, it was permissible to collapse items 14 and 18 into a single item. An Analysis of Variance (ANOVA) test was conducted with the combined Diversity items. As illustrated in Table 21, the ANOVA did not yield a statistically significant finding $(d f=2,313, F=.719, p=.488)$.

Table 21

Diversity, by Years

\begin{tabular}{lccc}
\hline Groups* & $\mathrm{N}$ & Mean & SD \\
One Year & 164 & 4.59 & 0.493 \\
Two Years & 95 & 4.66 & 0.485 \\
Three Years & 57 & 4.58 & 0.420 \\
& & & \\
\hline
\end{tabular}

$* d f=2,313, F=.719, p=.488$

Intrinsic Benefits. To determine if there were statistically significant differences in the category of Intrinsic Benefits, a Cronbach's Alpha test was administered to determine reliability of the category (Survey Items $27,34,37,38$ ). Reliability was 
acceptable for this category $(a=.749)$. Therefore it was permissible to collapse items 27 , 34, 37, 38 into a single combined item. An Analysis of Variance (ANOVA) test was conducted with the combined survey items. As illustrated in Table 22, the ANOVA did not yield a statistically significant finding $(d f=2,309, F=.954, p=.386)$.

Table 22

Intrinsic Benefits, by Years

$\begin{array}{lrcc}\text { Groups* } & \mathrm{N} & \text { Mean } & \mathrm{SD} \\ \text { One year } & 162 & 4.27 & 0.627 \\ \text { Two Years } & 94 & 4.34 & 0.509 \\ \text { Three Years } & 56 & 4.21 & 0.548 \\ & & & \end{array}$

Leadership Involvement. To determine if there were statistically significant differences in the category of Leadership Involvement, a Cronbach's Alpha test was administered to determine reliability of the category (Survey Items 35, 36). The alpha coefficient was less than the recommended score of .7 $(a=.690)$. Therefore, a mean interitem correlation was conducted and produced a score of .540 , which is above the acceptable level of homogeneity for this category. Some researchers are concerned that when the mean inter-item correlation score is over .5, the scale may be too redundant (Briggs \& Cheek, 1986). However, due to the fact there are only two survey items in this category which are similar in the pattern of responses, the researcher has decided to conduct only one ANOVA, using survey item 36. Since the responses to the two survey items are very similar, it is assumed that if an ANOVA was done for survey item 35, it would have very similar results to the ANOVA for survey item 36.

An Analysis of Variance (ANOVA) test was conducted with the Survey Item 36, ("I have increased my participation in leadership development opportunities, such as 
leadership courses and/or workshops") (see Table 23). The number of years the students served as peer mentors (one, two, three or more) represented the independent variable. The dependent variable was the survey item representing Leadership Development Opportunities (Survey Item 36). As illustrated in Table 23, the ANOVA did yield a statistically significant finding $(d f=2,312, F=3.750, p=.025)$.

Table 23

Leadership Involvement, by Years

\begin{tabular}{lrcc}
\hline Groups* & $\mathrm{N}$ & Mean & SD \\
One Year & 163 & 3.63 & 1.182 \\
Two Years & 95 & 4.02 & 1.082 \\
Three Years & 57 & 3.75 & 0.987 \\
\hline
\end{tabular}

$* d f=2,312, F=3.750, p=.025$

The results of a post hoc Tukey analysis found significance between peer mentors who served one year and peer mentors who have served two years as mentor $(p=.018)$. The two-year peer mentors reported a significantly greater agreement $(\mathrm{M}=4.02$; $\mathrm{SD}=1.082$ ) that they are involved in leadership opportunities more often than the oneyear peer mentors $(\mathrm{M}=3.63 ; \mathrm{SD}=1.182)$.

Reflection. To determine if there were statistically significant differences in the category of Reflection, a Cronbach's Alpha test was administered to determine reliability of the category (Survey Items 23, 25). Reliability was acceptable for this category $(a=.766)$. Therefore, it was permissible to collapse items 23 and 25 into a single item. An Analysis of Variance (ANOVA) test was conducted with the combined survey items. As illustrated in Table 24, the ANOVA did not yield a statistically significant finding $(d f=2,311, F=.195, p=.823)$. 
Table 24

Reflection, by Years

\begin{tabular}{lrcc}
\hline Groups* & $\mathrm{N}$ & Mean & $\mathrm{SD}$ \\
One year & 163 & 4.33 & 0.766 \\
Two Years & 94 & 4.38 & 0.637 \\
Three Years & 57 & 4.39 & 0.634
\end{tabular}

$* d f=2,311, F=.195, p=.823$

Student Engagement. To determine if there were statistically significant differences in the category of Student Engagement, a Cronbach's Alpha test was administered to determine reliability of the category (Survey Items 33, 39, 40, 41). Reliability was acceptable for this category $(a=.772)$. Therefore it was permissible to collapse items 33, 39, 40, 41 into a single combined item.

An Analysis of Variance (ANOVA) test was conducted with the combined survey items. As illustrated in Table 25, the ANOVA also did yield a statistically significant finding $(d f=2,307, F=3.07, p=.048)$.

Table 25

Student Engagement, by Years

\begin{tabular}{lccc}
\hline Groups* & $\mathrm{N}$ & Mean & SD \\
One year & 162 & 4.16 & 0.753 \\
Two Years & 92 & 4.35 & 0.573 \\
Three Years & 56 & 4.08 & 0.728
\end{tabular}

$* d f=2,307, F=3.070, p=.048$

The results of a post hoc Tukey analysis found significance in the category of Student Engagement between peer mentors who have served two years and peer mentors who have served at least three years as mentor $(p=.021)$. The two-year peer mentors reported a significantly stronger agreement $(\mathrm{M}=4.38 ; \mathrm{SD}=.573)$ that they were more engaged than the three-year peer mentors $(\mathrm{M}=4.08 ; \mathrm{SD}=.728)$. 
Research Question 4: Based on the peer mentors' university college (College of Education and Human Services; College of Science and Technology; College of Liberal Arts), is there a statistically significant difference in (a) satisfaction with the mentoring program staff, (b) satisfaction with the mentoring experience and (c) peer mentors' perceived learning and development?

For Research Question 4, a Cronbach's alpha test was administered to determine internal consistency amongst the items in that category. When the Cronbach's alpha was below the acceptable level of .7, the mean inter-item correlation was reported. Where permissible, either based on Cronbach's alpha or the mean inter-item correlation, the items for a scale were combined into a single item. Combining items into a single item negated the necessity for a MANOVA and allowed a single ANOVA to be computed for the combined item for the section of the survey. For example, for Satisfaction with the Mentoring Program Staff, items 44, 45, 47, and 48 were combined into a single item, Satisfaction with the Mentoring Program Staff.

Satisfaction. To determine if there was a statistically significant difference in peer mentors' satisfaction, based on the peer mentors' university college (College of Education and Human Services, College of Science and Technology, and College of Liberal Arts), satisfaction was divided into two categories: Satisfaction with mentoring Program Staff and Satisfaction with Mentoring Experience. Each of these two categories was treated separately for statistical analysis. The two categories of satisfaction constituted the dependent variable. The college in which the students' major was housed represented the independent variable. 
Satisfaction with Mentoring Program Staff, Based on College. To determine if there were statistically significant differences for Research Question 4a, a Cronbach's Alpha test was administered to determine reliability of the overall category of Satisfaction with the Mentoring Program Staff (Survey Items 44, 45, 47, 48). Reliability was acceptable for this category $(a=.802)$. Therefore, it was permissible to collapse items 44, 45, 47, and 48 into a single combined item. An Analysis of Variance (ANOVA) test was conducted with the combined survey items $(44,45,47,48)$. As illustrated in Table 26, the ANOVA did not yield a statistically significant finding $(d f=2,305, F=.360$, $p=.698)$.

Table 26

Satisfaction with Mentoring Program Staff, by College

Groups* N Mean SD

College of Education \& Human Services $167 \quad 4.57 \quad 0.527$

$\begin{array}{llll}\text { College of Science \& Technology } & 76 & 4.58 & 0.537\end{array}$

$\begin{array}{llll}\text { College of Liberal Arts } & 65 & 4.51 & 0.697\end{array}$

$* d f=2,305, F=.360, p=.698$

Satisfaction with Mentoring Experience, Based on College. To determine if there were statistically significant differences for Research Question 4b, a Cronbach's Alpha test was administered to determine reliability of the overall category of Satisfaction with the Mentoring Experience (Survey Items 43, 46, 49, 50). The alpha coefficient was less than the recommended score of .7 $(a=.646)$. Therefore, a mean interitem correlation was conducted and produced a score of .351 , which is within the acceptable level of homogeneity for this category. Thus, it was permissible to collapse items 43, 46, 49, and 50 into a single item. An Analysis of Variance (ANOVA) test was conducted with the combined Satisfaction with Mentoring Experience items. As 
illustrated in Table 27, the ANOVA did not yield a statistically significant finding $(d f=2$, $306, F=2.391, p=.093)$.

Table 27

Satisfaction with Mentoring Experience, by College

Groups* N Mean SD

College of Education \& Human Services $167 \quad 4.38 \quad 0.563$

$\begin{array}{llll}\text { College of Science \& Technology } & 75 & 4.52 & 0.471\end{array}$

$\begin{array}{llll}\text { College of Liberal Arts } & 67 & 4.31 & 0.746\end{array}$

$* d f=2,306, F=2.391, \mathrm{p}=.093$

Perceived Learning and Development, Based on College. To determine if there was a statistically significant difference in peer mentors' perceived learning and development, based on the peer mentors' university college (College of Education and human Services, College of Science, and Technology and College of Liberal Arts), the learning and development was divided into nine categories. These nine categories are: Academic Success, Collaboration, Communication Skills, Decision-Making and Problem-Solving, Diversity, Intrinsic Benefits, Leadership Involvement, Reflection, and Student Engagement, each of which was treated separately for statistical analysis. Each of these nine categories constituted the dependent variable. The college in which the students' major was housed represented the independent variable.

Academic Success. To determine if there were statistically significant differences in the category of Academic Success, first a Cronbach's Alpha test was administered to determine reliability of this category (Survey Items 24, 26, 28, 29, 30). The alpha coefficient was less than the recommended score of .7 ( $a=.699)$. Therefore, a mean interitem correlation was conducted and produced a score of .333 , which is within the acceptable level of homogeneity for this category. Thus, it was permissible to collapse 
items 24, 26, 28, 29 and 30 into a single item. An Analysis of Variance (ANOVA) test was conducted with the combined Academic Success items combined. As illustrated in Table 28, the ANOVA did not yield a statistically significant finding $(d f=2,305$, $F=1.389, p=.251)$.

Table 28

Academic Success, by College

Groups* N Mean SD

$\begin{array}{llll}\text { College of Education \& Human Services } & 165 & 4.18 & 0.567\end{array}$

$\begin{array}{llll}\text { College of Science \& Technology } & 73 & 4.18 & 0.615\end{array}$

$\begin{array}{llll}\text { College of Liberal Arts } & 70 \quad 4.04 & 0.708\end{array}$

$* d f=2,305, F=1.389, \mathrm{p}=.251$

Collaboration. To determine if there were statistically significant differences in the category of Collaboration, a Cronbach's Alpha test was administered to determine reliability of the category (Survey items 15,17 ). The alpha coefficient was less than the recommended score of .7 $(a=.421)$. Therefore, a mean inter-item correlation was conducted and produced a score of .268 , which is within the acceptable level of homogeneity for this category. Thus, it was permissible to collapse items 15 and 17 into a single item. An Analysis of Variance (ANOVA) test was conducted with the combined Collaboration items. As illustrated in Table 29, the ANOVA did not yield a statistically significant finding $(d f=2,311, F=1.442, p=.238)$. 
Table 29

Collaboration, by College

\begin{tabular}{lrrc}
\hline Groups* & N & Mean & SD \\
College of Education \& Human Services & 168 & 4.51 & 0.598 \\
College of Science \& Technology & 75 & 4.43 & 0.661 \\
College of Liberal Arts & 71 & 4.38 & 0.531 \\
& & & \\
\hline
\end{tabular}

$* d f=2,311, F=1.442, \mathrm{p}=.238$

Communication Skills. To determine if there were statistically significant differences in the category of Communication Skills, a Cronbach's Alpha test was administered to determine reliability of the category (Survey Items 20, 21, 22). The alpha coefficient was less than the recommended score of .7 $(a=.692)$. Therefore, a mean inter-item correlation was conducted and produced a score of .451 , which is within the acceptable level of homogeneity for this category. Thus, it was permissible to collapse items 20, 21, and 22 into a single item. An Analysis of Variance (ANOVA) test was conducted with the combined Communication Skills items. As illustrated in Table 30, the ANOVA did yield a statistically significant finding $(d f=2,309, F=3.142, p=.045)$.

Table 30

Communication Skills, by College

$\begin{array}{lrrc}\text { Groups* } & \text { N } & \text { Mean } & \text { SD } \\ \text { College of Education \& Human Services } & 168 & 4.38 & 0.544 \\ \text { College of Science \& Technology } & 75 & 4.45 & 0.607 \\ \text { College of Liberal Arts } & 69 & 4.21 & 0.700\end{array}$

$* d f=2,309, F=3.142, \mathrm{p}=.045$

The results of a post hoc Tukey analysis found significance in the Communication Skills category for peer mentors who are Science and Technology majors and peer mentors who are Liberal Arts majors as peer mentors $(p=.042)$. The College of Science 
and Technology peer mentors reported a significantly higher agreement $(M=4.45$; $\mathrm{SD}=.607)$ that they enhanced their Communication Skills than did the College of Liberal Arts peers mentors $(\mathrm{M}=4.21 ; \mathrm{SD}=.700)$.

Decision-Making and Problem-Solving. To determine if there were statistically significant differences in the category of Decision-Making and Problem-Solving, a Cronbach's Alpha test was administered to determine reliability of the category (Survey Items 16, 19, 31). The alpha coefficient was less than the recommended score of .7 $(a=.541)$. Therefore, a mean inter-item correlation was conducted and produced a score of .296, which is within the acceptable level of homogeneity for this category. Thus, it was permissible to collapse items 16, 19, and 31 into a single item. An Analysis of Variance (ANOVA) test was conducted with the combined Decision-Making and Problem-Solving items combined. As illustrated in Table 31, the ANOVA did not yield a statistically significant finding $(d f=2,304, F=1.270, p=.282)$.

Table 31

Decision-Making \& Problem-Solving, by College

\begin{tabular}{lrrc}
\hline Groups* & N & Mean & SD \\
College of Education \& Human Services & 165 & 4.21 & 0.555 \\
College of Science \& Technology & 75 & 4.20 & 0.608 \\
College of Liberal Arts & 67 & 4.08 & 0.609 \\
& & & \\
\hline
\end{tabular}

$* d f=2,304, F=1.270, \mathrm{p}=.282$

Diversity. To determine if there were statistically significant differences in the category of Diversity, a Cronbach's Alpha test was administered to determine reliability of the category (Survey Items 14, 18). The alpha coefficient was less than the recommended score of .7 ( $a=.315)$. Therefore, a mean inter-item correlation was conducted and produced a score of .188 , which is within the acceptable level of 
homogeneity for this category. Thus, it was permissible to collapse items 14 and 18 into a single item. An Analysis of Variance (ANOVA) test was conducted with the combined Diversity items. As illustrated in Table 32, the ANOVA did not yield a statistically significant finding $(d f=2,312, F=.145, p=.865)$.

Table 32

Diversity, by College

\begin{tabular}{lrrc}
\hline Groups* & N & Mean & SD \\
College of Education \& Human Services & 169 & 4.61 & 0.467 \\
College of Science \& Technology & 75 & 4.63 & 0.502 \\
College of Liberal Arts & 71 & 4.59 & 0.488
\end{tabular}

$* d f=2,312, F=.145, \mathrm{p}=.865$

Intrinsic Benefits. To determine if there were statistically significant differences in the category of Intrinsic Benefits, first, a Cronbach's Alpha test was administered to determine reliability of the category (Survey Items 27, 34, 37, 38). Reliability was acceptable for this category $(a=.749)$. Therefore it was permissible to collapse items 27 , 34, 37, 38 into a single combined item. An Analysis of Variance (ANOVA) test was conducted with the combined survey items. As illustrated in Table 33, the ANOVA did yield a statistically significant finding $(d f=2,308, F=3.715, p=.025)$.

Table 33

Intrinsic Benefits, by College

\begin{tabular}{lrrc}
\hline Groups* & N & Mean & SD \\
College of Education \& Human Services & 168 & 4.29 & .511 \\
College of Science \& Technology & 74 & 4.39 & .549 \\
College of Liberal Arts & 69 & 4.13 & .732
\end{tabular}

$* d f=2,308, F=3.715, \mathrm{p}=.025$ 
The results of a post hoc Tukey analysis found a significant difference in the category of Intrinsic Benefits between Science and Technology major peer mentors and Liberal Arts major peer mentors $(\mathrm{p}=.019)$. The College of Science and Technology peer mentors reported a significantly stronger agreement $(M=4.39 ; \mathrm{SD}=.549)$ that they gained intrinsic benefits than did the College of Liberal Arts peers mentors $(M=4.13 ; \mathrm{SD}=.732)$.

Leadership Involvement. To determine if there were statistically significant differences in the category of Leadership Involvement, a Cronbach's Alpha test was administered to determine reliability of the category (Survey Items 35, 36). The alpha coefficient was less than the recommended score of .7 $(a=.690)$. Therefore, a mean interitem correlation was conducted and produced a score of .540 , which is above the acceptable level of homogeneity for this category. Some researchers are concerned when the mean inter-item correlation score is over .5, the scale may be too redundant (Briggs \& Cheek, 1986). However, due to the fact there are only two survey items in this category which are similar in the pattern of responses, the researcher has decided to conduct only one ANOVA, using survey item 36. Since the responses to the two survey items are very similar, it is assumed that if an ANOVA was done for survey item 35, it would have very similar results to the ANOVA for survey item 36.

An Analysis of Variance (ANOVA) test was conducted with the Survey Item 36, ("I have increased my participation in leadership development opportunities, such as leadership courses and/or workshops") (see Table 34). The college in which the students' major was housed represented the independent variable. The dependent variable was the survey item representing Leadership Development Opportunities (Survey Item 36). As 
illustrated in Table 34, the ANOVA did not yield a statistically significant finding $(d f=2$, $311, F=1.789, p=.169)$.

Table 34

Leadership Involvement, by College

$\begin{array}{lrrc}\text { Groups* } & \text { N } & \text { Mean } & \text { SD } \\ \text { College of Education \& Human Services } & 168 & 3.80 & 1.112 \\ \text { College of Science \& Technology } & 76 & 3.89 & 1.150 \\ \text { College of Liberal Arts } & 70 & 3.56 & 1.137\end{array}$

$* d f=2,311, F=1.789, p=.169$

Reflection. To determine if there were statistically significant differences in the category of Reflection, a Cronbach's Alpha test was administered to determine reliability of the category (Survey Items 23, 25). Reliability was acceptable for this category $(a=766)$. Therefore, it was permissible to collapse items 23 and 25 into a single item. An Analysis of Variance (ANOVA) test was conducted with the combined survey items. As illustrated in Table 35, the ANOVA did yield a statistical significant finding $(d f=2$, $310, F=3.916, p=.021)$.

Table 35

Reflection, by College

\begin{tabular}{lrrc}
\hline Groups* & N & Mean & SD \\
College of Education \& Human Services & 169 & 4.41 & 0.661 \\
College of Science \& Technology & 76 & 4.43 & 0.570 \\
College of Liberal Arts & 68 & 4.15 & 0.894 \\
\hline
\end{tabular}

$* \mathrm{df}=2,310, \mathrm{~F}=3.916, \mathrm{p}=.021$

The results of a post hoc Tukey analysis found a significant difference in the category of Reflection between peer mentors who are College of Education majors and peer mentors who are College of Liberal Arts majors $(\mathrm{p}=.026)$. The College of Education 
and Human Services peer mentors reported a significantly higher agreement $(M=4.41$; $\mathrm{SD}=.661$ ) that they enhanced their reflection skills than did the College of Liberal Arts peer mentors $(\mathrm{M}=4.15 ; \mathrm{SD}=.894)$.

The results of the post hoc Tukey analysis also found a significant difference in the category of Reflection between peer mentors who are College of Science and Technology majors and peer mentors who are College of Liberal Arts majors $(p=.044)$. The College of Science and Technology peer mentors also reported a significantly higher agreement $(\mathrm{M}=4.43 ; \mathrm{SD}=.570)$ that they enhanced their reflection skills than did the College of Liberal Arts peer mentors $(\mathrm{M}=4.15 ; \mathrm{SD}=.894)$.

Student Engagement. To determine if there were statistically significant differences in the category of Student Engagement, a Cronbach's Alpha test was administered to determine reliability of the category (Survey Items 33, 39, 40, 41). Reliability was acceptable for this category $(a=.772)$. Therefore, it was permissible to collapse items 33, 39, 40, and 41 into a single item. An Analysis of Variance (ANOVA) test was conducted with the combined survey items. As illustrated in Table 36, the ANOVA also did yield a statistically significant finding $(d f=2,306, F=8.516, p=.000)$.

Table 36

Student Engagement, by College

\begin{tabular}{lrrc}
\hline Groups* & N & Mean & SD \\
College of Education \& Human Services & 165 & 4.28 & 0.608 \\
College of Science \& Technology & 75 & 4.32 & 0.624 \\
College of Liberal Arts & 69 & 3.91 & 0.901
\end{tabular}

$*_{\mathrm{df}}=2,306, \mathrm{~F}=8.516, \mathrm{p}=.000$

The results of a post hoc Tukey analysis found significant difference in the category of Student Engagement between peer mentors who are College of Education 
majors and peer mentors who are College of Liberal Arts majors $(p=.001)$. The College of Education and Human Services peer mentors reported significantly stronger agreement $(\mathrm{M}=4.28 ; \mathrm{SD}=.608)$ that they increased their student engagement than did the College of Liberal Arts peer mentors $(\mathrm{M}=3.91 ; \mathrm{SD}=.901)$.

The results of the post hoc Tukey analysis also found significant difference in the category of Student Engagement between peer mentors who are College of Science and Technology majors and peer mentors who are College of Liberal Arts majors $(p=.001)$. The College of Science and Technology peer mentors also reported stronger agreement $(\mathrm{M}=4.32 ; \mathrm{SD}=.624)$ that they increased their student engagement than did the College of Liberal Arts peer mentors $(\mathrm{M}=3.91 ; \mathrm{SD}=.901)$.

\section{Summary of Key Findings}

The purpose of this study was to examine satisfaction and perceived learning and development of university peer mentors who participated in a university peer mentoring program. In this research study, 317 peer mentors responded to an on-line survey instrument, Survey Regarding Satisfaction, Learning, and Development of Peer Mentors in Higher Education.

This study found that peer mentors agreed that they had enhanced their learning and development in academic success, collaboration, communication skills, decisionmaking and problem-solving, diversity, intrinsic benefits, and reflection. By contrast, over one-third of the peer mentors indicated they were neutral or disagreed that they were more involved in leadership opportunities. One-third of the peer mentors also reported they were neutral or disagreed that since becoming a peer mentor, they were more engaged in campus activities or felt more comfortable asking questions in class. 
Of the nine categories of learning and development, statistically significant differences were identified in two categories, based on years. Students who served two years as peer mentors reported higher agreement that they were more involved in leadership opportunities than one-year mentors. Two-year mentors also reported higher agreement that they were more engaged on campus than three-year mentors.

Statistically significant differences were identified in four learning and development categories, based on college. Science and Technology peer mentors reported stronger agreement than Liberal Arts peer mentors that their communication skills were enhanced. Science and Technology peer mentors also indicated stronger agreement that they gained in intrinsic benefits than did Liberal Arts peer mentors. Both Science and Technology and Education and Human Services peer mentors reported higher agreement than Liberal Art peer mentors that their reflection skills have been enhanced. Both Science and Technology and Education and Human Services peer mentors also reported stronger agreement than Liberal Arts peer mentors that they are more engaged on campus. 


\section{Chapter 5}

\section{Summary, Conclusions, and Recommendations}

This chapter presents a summary, conclusions, and implications of this dissertation study. First, an overview of this study will be presented followed by the findings related to the literature. Next, this chapter will provide a discussion of the implications for action and recommendations for further research.

\section{Summary}

The purpose of this study was to examine satisfaction and perceived student learning and development of student peer mentors from a peer mentoring program in higher education. This study also examined whether there was a statistical significant difference in satisfaction and the perceived learning and development based on the peer mentors' university college (College of Education and Human Service, College of Science and Technology, or College of Liberals Arts) and based on the number of years they served as a peer mentor (one, two, three or more).

This study was conducted at a master's level, public university which has an extensive peer mentoring program designed to assist new students with the transition to the university. The peer mentors are primarily traditionally-aged students (under the age of 25), and the majority of these students live on or near campus. An on-line survey, which measured satisfaction and perceived learning and development, Survey Regarding Satisfaction, Learning and Development of Peer Mentors in Higher Education, was distributed to 600 student peer mentors during the spring 2011 semester. Over $50 \%$ $(\mathrm{N}=317)$ of peer mentor responses were used in the study. 
Four major research questions examined satisfaction and perceived learning and development of university peer mentors. The first research question focused on the peer mentors' perceived learning and development. The nine categories of learning and development were: Academic Success, Collaboration, Communication Skills, DecisionMaking and Problem-Solving, Diversity, Intrinsic Benefits, Leadership Involvement, Reflection, and Student Engagement. Across seven of the nine categories of learning and development, the majority of peer mentors perceived gains. By contrast, for two categories, over one-third of the peer mentors indicated they were neutral or disagreed that they were more involved in leadership opportunities. One-third of the peer mentors also reported they were neutral or disagreed that since becoming a peer mentor, they were more engaged in campus activities or felt more comfortable asking questions in class.

The second research question focused on the peer mentors' satisfaction with the mentoring program staff and the mentoring experience. Peer mentors reported that they were satisfied with both the mentoring program staff and the mentoring experience.

The third research question investigated whether significance existed in peer mentors' satisfaction of the mentoring program staff, satisfaction of their mentoring experience, and perceived learning and development, based on peer mentors' years they served as a peer mentor (one, two, three or more). No significance existed in either of the categories of satisfaction, based on the number of years students served as peer mentors. However, significance was reported in two of the nine learning and development categories, based on years. Students who served two years as peer mentors reported higher agreement that they were more involved in leadership than one-year mentors. 
Two-year mentors also reported higher agreement that they were more engaged on campus than three-year mentors.

The fourth research question examined whether significance existed in peer mentors' satisfaction of the mentoring program staff, satisfaction of their mentoring experience and their perceived learning and development, based on the college in which their major is housed (College of Education and Human Services, College of Science and Technology, College of Liberal Arts). No significance existed in either of the categories of satisfaction, based on the college in which their major is housed. However, significance was reported in four of the nine learning and development categories. Science and Technology peer mentors reported stronger agreement than Liberal Arts peer mentors, that their communication skills were enhanced. Science and Technology peer mentors also indicated stronger agreement that they gained in intrinsic benefits, than did Liberal Arts peer mentors. Both Science and Technology and Education and Human Services peer mentors reported higher agreement than Liberal Art peer mentors that their reflection skills have been enhanced. Both Science and Technology and Education and Human Services peer mentors also reported stronger agreement than Liberal Arts peer mentors that they are more engaged on campus.

\section{Conclusions: Learning and Development}

Through mentor training workshops and interactions with their assigned protégés, peer mentors are exposed to practical experiences which can develop skills that are transferrable to their college major or future employment (Harmon, 2006). The mentoring experience can be seen as an opportunity to develop in areas such as communication, problem solving, teamwork and leadership (Harmon, 2006). These skills 
are viewed as essential to employers (Carnevale, Gainer, \& Meltzer, 1990; Hansen \& Hansen, 2011). Ideally, peer mentors are provided with opportunities to develop skills and enhance their personal and academic successes (Terrion, et al., 2007).

Academic Success. This dissertation study found that peer mentors perceived that since becoming mentors, their academic success has been enhanced. Nearly $88 \%$ of the peer mentors strongly agreed or somewhat agreed that they were more aware of university resources (such as the writing center, math lab, reading center, advisement center or tutoring center) and $67 \%$ strongly agreed or somewhat agreed that they utilized these resources. These findings are consistent with the results of Terrion, Philion, and Leonard (2007) of the University of Ottawa's peer-mentoring training program. Terrion, et al. (2007) found that peer mentors indicated that due to their participation in mentoring training, they had increased their competencies in understanding university resources. However, nearly one-third disagreed that they utilized the resources more often.

The researcher of this dissertation study also found that peer mentors felt that they were more effective in their time management and organizational skills since becoming a mentor. These findings are similar to McKinney and Reynolds (2002), who found that peer mentors had increased awareness of their personal learning styles which had a positive impact on their time management skills and study habits. There were no significant differences based on peer mentors' college or years of service in the Academic Success category.

Collaboration. Peer mentors, from this dissertation study, indicated that they collaborate with colleagues and peers and value working collaboratively with others. Studies (Harmon, 2006; Heirdsfield, et al., 2008) have found that peer mentoring 
programs lend themselves to collaborative endeavors. Through mentor training programs and mentor meetings, peer mentors identified that they worked collaboratively with fellow peer mentors to discuss effective mentoring strategies (Harmon, 2006), establish networks (Terrion, et al. 2007) and discuss solutions to specific situations or problems (Heirdsfield, et al., 2008). Heirdsfield, et al. (2008) also found that peer mentors felt that meetings with their peers also helped them to establish an academic and social support system. There were no significant differences based on peer mentors' college or years of service in Collaboration category.

Communication Skills. Peer mentors reported $92.8 \%$ strongly or somewhat agreed that their listening skills had improved since becoming a peer mentor. Jones and Kolko (2002) had similar findings in their 2002 study at Indiana University in which student peer mentors expressed more confidence in their communication abilities.

In addition, CAS identifies "communicating effectively" as a practical competence of college students' learning and development (Dean, 2009, p. 28). A mentoring relationship provides opportunities for peer mentors to engage and interact with other mentors and protégés. Therefore, it is essential that students who serve as peer mentors have effective communication skills to maintain a successful mentoring relationship (Allen \& Poteet, 1999; Harris \& Crocker, 2003; Heirdsfield, et al., 2008; Mee-Lee \& Bush, 2003; Terrion \& Leonard, 2007). According to Harmon (2006), mentors' interactions with their protégés provide opportunities for the peer mentors to improve their communication skills, particularly their interpersonal communication skills (Harmon, 2006). The findings from this dissertation study reinforce Harmon's statements. 
Within the category of Communication Skills, significant differences emerged between peer mentors in the College of Science and Technology and the peer mentors in the College of Liberal Arts. College of Science and Technology peer mentors reported stronger agreement that they had enhanced communication skills than the College of Liberal Arts peer mentors.

Decision-Making and Problem-Solving. The majority (95\%) of peer mentors reported that they strongly or somewhat agreed that they assisted their protégés with decision-making and problem solving, and $80.3 \%$ of the peer mentors reported that their personal decision-making and problem-solving skills had improved since becoming a peer mentor.

Many mentoring programs conduct on-going group training meetings with the peer mentors which discuss decision-making and problem-solving skills. In addition, researchers, such as Harmon (2006) and Terrion, et al. (2007) find that as a result of meeting on a regular basis, the students become part of a learning community with fellow peer mentors who learn from each other on how to problem-solve and how to prevent potential concerns. In this dissertation study, there were no significant differences based on peer mentors' college or years of service in the decision-making and problem-solving category.

Diversity. Peer mentors indicated that they had the opportunity to meet and work with people who were different from themselves. Within a mentoring program, peer mentors are assigned students who come with different backgrounds, issues, and learning styles (Harmon, 2006). According to Harmon (2006), peer mentors should ideally understand and appreciate the differences of each of their protégés. 
This dissertation study also found that peer mentors indicated that they adapt their mentoring approach to meet the needs of their protégés. These findings are consistent with Harmon's (2006) findings in which peer mentors indicated that they learned to adapt their mentoring approach to address the various issues and concerns of each student they assisted. No significant differences were reported in diversity, based on the peer mentors' college or years of service.

Intrinsic Benefits. In this dissertation study, the majority $(85.7 \%)$ peer mentors self-reported that they strongly or somewhat agreed that being a mentor enhanced their overall college experience. The results of this study indicated that peer mentors felt that they have increased self-confidence $(M=4.16)$, increased confidence in their abilities to lead others $(\mathrm{M}=4.36)$, as well as increased confidence in their abilities to solve problems $(M=4.23)$. These results are consistent with Gilles and Wilson's (2004) findings, as well as Allen, Russell and Maetzke's (1997) conclusions that individuals who served as mentors indicated a gain in their sense of self-worth and enhanced confidence in their own abilities.

Furthermore, in this dissertation study significance was found in the category of Intrinsic Benefits between the College of Science and Technology and Liberal Arts peer mentors. The College of Science and Technology peer mentors reported higher levels of agreement that they had enhanced intrinsic benefits than the College of Liberal Arts peer mentors.

Leadership Involvement. Over one-third were neutral or disagreed that they have held one leadership position in a student organization; while nearly $40 \%$ of the students either were neutral or disagreed that they participated in leadership development 
opportunities (such as leadership courses and/or workshops). These findings are less than what would be expected of peer mentors.

Significant differences were identified between the one-year and two-year peer mentors. The two leadership involvement survey items questioned whether the peer mentors perceived that they had become more involved in leadership roles or engaged in more leadership development opportunities since becoming a peer mentor. These findings would imply that once students become peer mentors, they tend to engage in more leadership opportunities.

Reflection. Peer mentors from this dissertation study indicated that they were more aware of how they learn and study and adapted their study skills to enhance academic success. The peer mentors also reported they were more aware of their own skills and abilities. Within the structure of many mentoring programs, peer mentors are encouraged to reflect on their interactions with their protégés and their own learning (Harmon, 2006; Heirdsfield, Walker, Walsh \& Wilss, 2008; Terrion, et al., 2007; Zachary, 2000). The findings of this dissertation study were consistent with Heirdsfield, et al. (2008) in a study of first-year teacher education students conducted at Queensland University of Technology, in which it was found that peer mentors indicated through reflections of their mentoring training and subsequent mentoring relationships that they became more aware of their own competencies and study skills.

This dissertation study also identified significant differences between the College of Education and Human Services peer mentors and Liberal Arts peer mentors. The researcher speculates that education students, as future teachers, are taught to reflect in the classroom setting and transfer these skills to outside of the classroom settings. 
Student Engagement. Peer mentors from this dissertation study indicated that they know more students in their academic department $(\mathrm{M}=4.43)$ since becoming a peer mentor. They also reported that they are comfortable interacting with professors $(\mathrm{M}=4.02)$ and are comfortable asking questions in class $(\mathrm{M}=4.02)$. These findings are similar to the study conducted at University of Ottawa by Terrion, Philion, and Leonard (2007) in which peer mentors indicated that they felt more connected to the university faculty as a result of their participation in the mentoring program.

By contrast, one-third of the peer mentors were neutral or disagreed that they participated in campus activities more often. Another one-third was neutral or disagreed that they were more comfortable asking questions in class.

There was a significant difference in the category of Student Engagement between the two-year and three-year mentors. Two-year peer mentors reported higher agreement than three-year peer mentors that they were more engaged on campus. There were also significant differences between the Education and Human Services and Liberal Arts peer mentors. Education and Human Services peer mentors reported higher agreement than Liberal Arts peer mentors that they were also more engaged on campus.

Of the nine categories of learning and development, statistically significant differences were only found in the category of Leadership Involvement and the category of Student Engagement, based on the number of years the students served in the role of peer mentor (see Table 37). 
Table 37

Statistically Significant Differences, Based on Years

One Year
Leadership Involvement
Student Engagement

Statistically significant differences were also found in four categories, Communication Skills, Intrinsic Benefits, Reflection, and Student Engagement, based on the college in which the students' majors are housed (see Table 38).

Table 38

Statistically Significant Differences, Based on College

Education

\& Human

Services

Communication Skills

Intrinsic Benefits

Reflection

Student Engagement
Science \& Technology
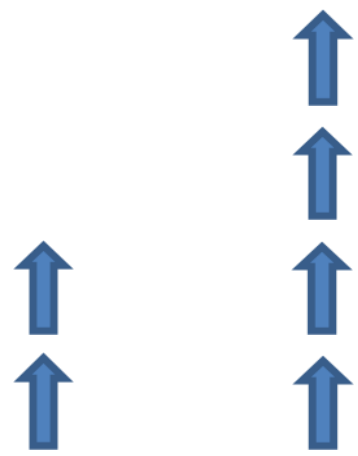

Liberal Arts

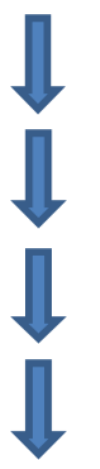

Another interesting finding is the consistent trend that occurred when examining differences between the colleges. In each case in which significance was found, the College of Liberal Arts was one of the three colleges that illustrated differences. In 
addition, in each of the four statistically significant different findings, the College of Liberal Art peer mentors had less agreement than the other colleges.

\section{Conclusions: Satisfaction}

Individuals who serve in the role of peer mentor describe it as a satisfying experience (Heirdsfield, el at., 2008; Mee-Lee \& Bush, 2003). Studies have reported that mentors enjoyed observing others succeed (Allen, Poteet, \& Burroughs, 1997) and facilitating student learning (Atkins \& Williams, 1995, p. 1011). In a review of the literature by Ehrich, Hansford, and Tennet (2004), personal satisfaction, reward, or growth was one of the most frequently cited outcomes for mentors. This dissertation study provides more in-depth feedback on peer mentors' satisfaction. Satisfaction was coded into two categories: Satisfaction with the Mentoring Program Staff and Satisfaction with the Mentoring Experience.

Satisfaction with the Mentoring Program Staff. Peer mentors indicated that they were satisfied with the mentoring program staff $(M=4.56)$. They found the mentoring staff to be friendly and approachable $(M=4.70)$ and helpful $(M=4.60)$. They also indicated that they were satisfied with the weekly information provided to them $(\mathrm{M}=4.42)$ and were satisfied with the time it takes for the mentoring program staff to respond to questions and concerns $(\mathrm{M}=4.53)$. No significant differences were identified based on the numbers of years a student served as a mentor or based on the college in which their major was housed.

Satisfaction with the Mentoring Experience. Peer mentors also indicated that they are satisfied with the mentoring experience $(M=4.40)$. Nearly $90 \%$ of the peer mentors strongly agreed or somewhat agreed that they were adequately trained to serve in 
the mentor role. Over $90 \%$ of the peer mentors reported that they were satisfied with the overall mentoring experience. These findings are consistent with Knowles and Parson's (2009) study of peer mentors in English secondary schools in which peer mentors stated they were satisfied with preparation to serve as a peer mentor and were satisfied to serve in this role. No significant differences were identified based on the numbers of years a student served as a mentor or based on the college in which their major was housed.

\section{Limitations of the Results}

This dissertation presented peer mentors' self-reported responses and they tended to be very high. These high scores could be influenced by a number of reasons. First, the peer mentors may have provided responses that present a positive reflection on their own abilities and opinions (Cook \& Campbell, 1979). Second, the peer mentors may have wanted to report what they thought the researcher expected (Cook \& Campbell, 1979). Third, the Hawthorne Effect could also be a consideration for the high scores. This theory implies that individuals' behaviors may improve for the mere fact that they are being studied, not because of any particular experimental manipulation (Gay, 1996). Fourth, the primary researcher for this study also served as the administrator of the mentoring program in this study. Fifth, the peer mentors who did respond are most likely the students who were most engaged in their mentoring relationships. Finally, some of the items should have had levels of frequency options instead of levels of agreement in the on-line survey. In some cases, the "agreement" options may have been confusing to the respondents. 


\section{Implications for Practitioners and Future Studies}

Little quantitative research is available that examines learning and development of university peer mentors. This study has a compilation of learning and development categories that were derived from primarily qualitative studies (Harmon, 2006;

Heirdsfield, et al., 2008; McKinney \& Reynolds, 2002, Terrion, Philion, \& Leonard, 2007; Gilles \& Wilson, 2004) that focused on various components in learning and development of university peer mentors. According to Harmon (2006), assessment tools are needed to measure learning outcomes for peer mentors. A survey instrument, Survey Regarding Satisfaction, Learning, and Development of Peer Mentors in Higher

Education, was created based on satisfaction of the mentoring program staff and mentoring experience and nine categories of learning and development derived from the literature.

Implication for Practitioners. When considering applications of this instrument and study for future practice, administrators should take into consideration that this study was based on one institution's peer mentoring program. The design of this program may be different than other university-based peer-mentoring programs. Therefore, results from this study are not generalized to all colleges and universities.

First, a revised survey instrument should be created which provides levels of agreements and/or levels of frequencies based on the survey item stem. For example, items concerning engagement and involvement should have frequency response choices instead of agreement choices, which was originally indicated in this survey.

Second, practitioners can utilize the revised Survey Regarding Satisfaction, Learning, and Development of Peer Mentors in Higher Education instrument (or an 
adapted version of the instrument) to measure a comprehensive perspective of the learning and development of the students who serve as peer mentors. Again, some of the response choices should be changed rather than using only agreement statements. Results of the instrument can help practitioners to identify areas of improvement.

Third, practitioners can also adapt the revised Survey Regarding Satisfaction, Learning, and Development of Peer Mentors in Higher Education instrument to conduct a pre-assessment of self-reported learning outcomes of students prior to starting their role as mentors. A post-assessment of self-reported learning outcomes can be administered after the students have completed one year of service as a peer mentor. Results of the post-assessment self-report can guide practitioners to adapt mentor training and communication with the peer mentors which focus on areas of deficiency.

Fourth, through the use of the revised instrument, Survey Regarding Satisfaction, Learning, and Development of Peer Mentors in Higher Education, this study also examined how satisfied peer mentors were with the mentoring program staff and the mentoring program experience. Practitioners can utilize the satisfaction component of the instrument to identify specific satisfaction issues that need to be addressed. For example, within this study peer mentors indicated that they were neutral or disagreed that they were satisfied with their protégé match. The administrators at HSU can use this information to provide more careful consideration when matching mentors with protégés.

Fifth, the peer mentoring program administered at HSU can use this information to re-examine how their peer mentors are encouraged to engage in leadership opportunities and evaluate how the mentoring program administrators are emphasizing leadership opportunities to peer mentors. 
Sixth, the peer mentoring program administrators at HSU can re-examine overall student engagement and evaluate how the mentoring program administrators are facilitating and encouraging student engagement, in- and out-of the classroom.

Seventh, the peer mentoring program administrators at HSU should further examine why Liberal Arts peer mentors at HSU reported less agreement than the Education and Human Services and Science and Technology peer mentors in regards to communication skills, intrinsic benefits, reflection and student engagement. Of the majors within the College of Liberal Arts that responded to the survey, $25 \%$ of the respondents were Justice Studies' majors and 21\% of the respondents were Communication Studies' majors. It is recommended that the HSU peer mentoring program administrators interview faculty members and students from these majors to further investigate the lower levels of agreement.

Recommendations for Future Studies. These findings underscore that peer mentors at Hillview State University perceive that they are enhancing their skills in the nine categories of learning and development identified in this study. However, additional work is necessary to determine the validity of the instrument.

The first recommendation for future research is to examine the number of hours associated with the mentor training programs and the amount of time students spend in their roles as a peer mentor in relationship to learning and development. It is also recommended that consideration be given to the learning and development of students based on various roles and positions they hold on campus.

The second recommendation for a possible study is to examine the nine categories of learning and development to measure differences amongst various university peer 
mentor populations, such as peer mentors' specific academic departments, particular affinity groups, or athletics or could compare peer mentors' quality point average to their perceived level of learning and development.

The third recommendation for research is to compare peer mentors' levels of student engagement in comparison to other groups on campus. The results of this survey could be compared with some of the responses to the National Survey of Student Engagement (NSSE) to see if there are correlations between students' mentoring experiences and their responses on this national survey.

The fourth recommendation for future study is to conduct a longitudinal study which follows a cohort of students as protégés, to first year mentors, second year mentors and third year mentors to provide direct assessment of student learning outcomes.

The fifth recommendation is to further investigate whether Liberal Arts peer mentors at other institutions report less agreement than the Education and Human Services and Science and Technology peer mentors in regards to learning and development. 


\section{References}

Allen, T. D., Poteet, M. L., \& Burroughs, S. M. (1997). The mentor's perspective: A qualitative inquiry and future research agenda. Journal of Vocational Behaviors, 55(1), 70-89.

Allen, T. D., Russell, J. E. A., \& Maetzke, S. B. (1997). Formal peer mentoring: factors related to protégés' satisfaction and willingness to mentor others. Group \& Organization Management, 22(4), 488-508.

American College Personnel Association (1996). Student learning imperative. Implications for student affairs. Retrieved from http://www.acpa.nche.edu/sli/sli.htm

Astin, A. W. (1984). Student involvement: A development theory for higher education. Journal of College Student Personnel, 25(4), 297-308.

Atkins, S., \& Williams, A. (1995). Registered nurses' experiences of mentoring undergraduate nursing students. Journal of Advanced Nurses, 21(5), 1006-1015.

Awe, C. (2003). Mentoring and show programs for academic professional and faculty interested in administration. Proceedings of the International Mentoring Association. 14-17.

Berger, J. B., \& Milem, J. F. (1999). The role of student involvement and perceptions of integration in a causal model of student persistence. Research in Higher Education, 40(6), 641-664. 
Bernstein, L., Rappaport, C. D., Olsho, L., Hunt, D., \& Levin, M. (2009, March). Impact evaluation of the U.S. Department of Education's student mentoring program. National Center for Education Evaluation and Regional Assistance. Washington, DC: U.S. Department of Education.

Bresciani, M. J., Zelna, C. L., \& Anderson, J. A. (2004). Assessing student learning and development: A handbook for practitioners. Washington, D.C.: National Association of Student Personnel Administrators.

Briggs, S. R., \& Cheek, J. M. (1986). The role of factor analysis in the development and evaluation of personality scales. Journal of Personality, 54(1), 106-148.

Buffalo State University (2010). Peer mentor program. Retrieved from www.buffalostate.edu/firstyearprograms/x521.xml

Campbell, D. E., \& Campbell, T. A. (2000). The mentoring relationship: Differing perceptions of benefits. College Student Journal, 34(4), 516-524.

Campbell, D. E., \& Campbell, T. A. (2007). Outcomes of mentoring at-risk college students: Gender and ethnic matching effects. Mentoring \& Tutoring: Partnership in Learning, 15(2), 135-148.

Canton, M. E., \& James, D. P. (2008). Mentoring in higher education: Best practices (2nd ed.). Largo, MD: James/Canton Productions.

Carnegie Foundation for the Advancement of Teaching (2011). The classification of institutions of higher education. Retrieved from http://classifications.carnegiefoundation.org/

Carnevale, A. P., Gainer, L. J., \& Meltzer, A. S. (1990). The essential skills employers want. San Francisco: Jossey-Bass. 
Chickering, A. W., \& Reisser, L. (1993). Education and identity (2nd ed.). San Francisco: Jossey-Bass.

Cohen, N. H., \& Galbraith M. W. (1995). Mentoring in the learning society. In M. W. Galbraith \& N. H. Cohen (Eds.), Mentoring: New strategies and challenges (pp. 5-14). San Francisco: Jossey-Bass.

Conrady, L. L. (2007). A phenomenological case study of mentoring outcomes: Benefiting the mentor in student development, self-esteem, and identity formation. Dissertation Abstracts International, Section A. The Humanities and Social Sciences, 69(09), 3471.

Cook, T. D., \& Campbell, D. T. (1979). Quasi-experimentation: Design and analysis issues. Boston, MA: Houghton Mifflin Company.

Creswell, J. W. (2003). Research design: Qualitative, quantitative, and mixed methods approaches (2nd ed.). Thousand Oaks, CA: Sage Publications.

Crisp, G. (2009). Conceptualization and initial validation of the college student mentoring scale (CSMS). Journal of College Student Development, 15(2), 177194.

Crisp, G., \& Cruz, I. (2009). Mentoring college students: A critical review of the literature between 1990 and 2007. Research in Higher Education, 50(6), 525-545.

Cropper, A. (2000). Mentoring as an inclusive device for the excluded: Black students' experience of a mentoring scheme. Social Work Education, 19(6), 597-607.

Cullen, D. L. (1993). Women mentoring in academe: Addressing the gender gap in higher education. Gender and Education, 5(2), 125-137. 
Daloz, L. A. (1999). Mentor: Guiding the journey of adult learners (2nd ed.). San Francisco: Jossey-Bass.

Dean, L. A. (Ed.). (2009). The CAS book of professional standards for higher education (7th ed.). Washington, D.C.: Council for the Advancement of Standards in Higher Education.

de Janasz, S. C., Ensher, E. A., \& Heun, C. (2008). Virtual relationships and real benefits: Using ementoring to connect business students with practicing managers. Mentoring \& Tutoring: Partnership in Learning, 16(4), 394-411.

DePauw University (2010). Mentor program. Retrieved from http://www.depauw.edu/fye/first-year/Mentors/Mentors.asp

Ehrich, L. S., Hansford, B., \& Tennent, L. (2004). Formal mentoring programmes in education and other professions: A review of the literature. Educational Administration Quarterly, 40, 518-540.

Evans, N. J., Forney, D.S., \& Guido-DiBrito, F. G. (1998). Student development in college. Theory, research, and practice. San Francisco: Jossey-Bass.

Ewing, R., Freeman, M., Barrie, S., Bell, A., O’Connor, D., Waugh, F., \& Sykes, C. (2008). Building community in academic settings: The importance of flexibility in a structured mentoring program. Mentoring \& Tutoring: Partnership in Learning, 16(3), 294-310.

Foubert, J. D., \& Grainger, L. U. (2006). Effects of involvement in clubs and organizations on the psychosocial development of first-year and senior college students. NASPA Journal, 42(1), 166-182. 
Gabriel, M. A., \& Kaufield, K. J. (2008). Reciprocal mentorship: An effective support for online instructors. Mentoring \& Tutoring: Partnership in Learning, 16(3), 311-327.

Gay, L. R. (1996). Educational research: Competencies for analysis and application (5th ed.). New Jersey: Prentice-Hall, Inc.

Gilles, C., \& Wilson, J. (2004). Receiving as well as giving: Mentors' perceptions of their professional development in one teacher induction program. Mentoring and Tutoring, 12(1), 87-106.

Girves, J. E., Zepeda, Y., \& Gwathmey, J. K. (2005). Mentoring in a post-affirmative action world. Journal of Social Issues, 61(3), 449-479.

Gonzalez-Rodriquez, Y. E. (1995). Mentoring to diversity: A multicultural approach. In M. W. Galbraith \& N. H. Cohen (Eds.), Mentoring: New strategies and challenges (pp. 69-78). San Francisco: Jossey-Bass.

Greene, H. C., O’Connor, K. A., Good, A. J., Ledford, C. C., Peel, B. B., \& Zhang, G. (2008). Building a support system toward tenure: Challenges and needs of tenure-track faculty in college of educations. Mentoring \& Tutoring: Partnership in Learning, 16(4), 429-447.

Habley, W. R., \& McClanahan, R. (2004). What works in student retention? Fouryear public colleges. American College Testing, Inc. Retrieved from http:/www.act.org/path/postsec/droptables/pdf/fouryearpublic.pdf.

Hansen, R. S., \& Hansen, K. (2009). What do employers really want? Top skills and values employers seek from job-seekers. Retrieved from http://www.quintcareers.com/job_skills_values.html. 
Hargraves, E. (2010). Knowledge construction and personal relationship: Insights about a UK university mentoring and coaching service. Mentoring \& Tutoring: Partnership in Learning, 18(2), 107-120.

Harmon, B. V. (2006). A qualitative study of the learning processes and outcomes associated with students who serve as peer mentors. Journal of the First-Year Experience \& Students in Transition, 18(2), 53-82.

Harris, S. (2002). Student perceptions of the mentoring relationship in higher education. In F. K. Kochan (Ed.), The organizational and human dimensions of successful mentoring programs and relationships (pp. 53-68). Greenwich, CT: Information Age Publishing.

Harris, S., \& Crocker, C. (2003). Benefits to mentors: It's like I have a legacy. Planning \& Changing, 34(1\&2), 70-83.

Harter, J. L., \& Jones-Walker, J. (2000). The influence of intensive faculty-guided mentoring program on the college adjustment of at-risk students: A qualitative assessment. (Journal Code RIEOCT2001). Toledo, OH: Mercy College of Northwest Ohio. (ERIC Document Reproduction Service No. ED452941)

Hayes, R. W., Wahlen, S. K., \& Cannon, B. (2009, May). 2008-09 CSRDE Retention report: The retention and graduation rates of entering baccalaureate degreeseeking freshman cohorts from fall 2000 through fall 1007 in 424 colleges and universities. Consortium for Student Retention Data Exchange Report. Norman, OK: The University of Oklahoma Outreach. 
Heirdsfield, A. M., Walker, S., Walsh, K., \& Wilss, L. (2008). Peer mentoring for firstyear teacher education students: the mentors' experience. Mentoring \& Tutoring: Partnership in Learning, 16(2), 109-124.

Hek, G. \& Moule, P. (2006). Making sense of research: An introduction for health and social care practitioners (3rd ed.). Thousand Oaks, CA: Sage Publications.

Huba, M. E., \& Freed, J. E. (2000). Learner-centered assessment on college campuses: Shifting the focus from teaching to learning. Boston: Allyn and Bacon.

Jacobi, M. (Winter, 1991). Mentoring and undergraduate academic success: A literature review. Review of Education Research, 61(4), 505-532.

Johnson, A. W., \& Sullivan, J. A. (1995). Mentoring program practices and effectiveness. In M. W. Galbraith \& N. H. Cohen (Eds.), Mentoring: New strategies and challenges (pp. 43-56). San Francisco: Jossey-Bass.

Johnson, W. B. (2003). A framework for conceptualizing competence to mentor. Ethics and Behavior, 13(2), 127-151.

Joint Task Force on Student Learning (1998). Powerful partnerships: A shared responsibility for learning. Washington, D.C.: National Association of Student Personnel Administrators.

Jones, M. H., \& Kolko, V. B. (2002). The psychosocial growth of peer mentors in a college program for students on academic probation. Unpublished manuscript, Indiana University. Retrieved from http://www.indiana.edu/ educy520/sec5982/week_15/mjvk.pdf 
Kerr, K. M., Schulze, D. R., \& Woodward, L.E. (1995). Organizationally sponsored mentoring. In M. W. Galbraith \& N. H. Cohen (Eds.), Mentoring: New strategies and challenges (pp. 33-42). San Francisco: Jossey-Bass.

Keeling, R. P. (Ed.) (2004). Learning reconsidered: Campus-wide focus on the student experience. Washington, DC: ACPA Advancing Student Affairs, Engaging Students \& NASPA Student Affairs Administrators in Higher Education.

Knowles, C., \& Parsons, C. (2009). Evaluating a formalised peer mentoring programme: student voice and impact audit. Pastoral Care in Education, (27)2, 205-218.

Kram, K. E. (1988). Mentoring at work: Developmental relationships in organizational life. Lanham, MD: University Press of America, Inc.

Kuh, G. D. (2005). Student engagement in the first year of college. In M. L. Upcraft, J. N. Gardner, B. O. Barefoot, \& Associates (Eds.), Challenging \& supporting the first-year student: A handbook for improving the first year of college (pp. 86107). San Francisco: Jossey-Bass.

Levitz, R., \& Noel, L. (1990). Connect students to institutions: Keys to retention and success. In Upcraft, M. L., Gardner, J. N. \& Associates (Eds.), The freshman year experience (pp. 65-81). San Francisco: Jossey-Bass.

Liu, D., Liu, J., Kwan, H. K., \& Mao, Y. (2009). What can I gain as a mentor? The effect of mentoring on the job performance and social status of mentors in China. Journal of Occupational and Organizational Psychology, 82(4), 871-395. McKinney, J. S., \& Reynolds, P. J. (2002). Rising from the ashes: The effects of peer experience in the Phoenix Program. Unpublished manuscript, Indiana University. Retrieved from http://www.indiana.edu/ educy520/sec5982/week_15/pauline.pdf 
McLean, M. (2004). Does the curriculum matter in peer mentoring? From mentee to mentor in problem-based learning: a unique case study. Mentoring \& Tutoring: Partnership in Learning, 12(2), 173-186.

Mee-Lee, L., \& Bush, T. (2003). Student mentoring in higher education: Hong Kong Baptist University. Mentoring \& Tutoring: Partnership in Learning, 11(3), 263271.

Miller, T. K. (Ed.). (2003). The CAS book of professional standards for higher education (3rd ed.). Washington, D.C.: Council for the Advancement of Standards in Higher Education.

Murray, M. (1991). Beyond the myths and magic of mentoring: How to facilitate an effective mentoring program. San Francisco: Jossey-Bass.

National Center for Education Statistics (2011). Definitions and data. Who is nontraditional? Retrieved from http://NCES.ed.gov/pubs/web/97578e.asp

Packard, B. W., Walsh, L., \& Seidenberg, S. (2004). Will that be one mentor or two? A cross-sectional study of women's mentoring during college. Mentoring \& Tutoring: Partnership in Learning, 12(1), 71-85.

Pallant, J. (2007). SPSS survival manual. A step by step guide to data analysis using SPSS for windows ( $3^{\text {rd }}$ ed.). New York: McGraw-Hill.

Patten, M. L. (2002). Understanding research methods: An overview of the essentials (3rd ed.). Los Angeles, CA: Pyrczak Publishing. 
Peterson, S. M., Valk, C., Baker, A. C., Brugger, L., \& Hightower, A. D. (2010). "We're not just interested in the work." Social and emotional aspects of early educator mentoring relationships. Mentoring \& Tutoring: Partnership in Learning, 18(2), 155-175.

Posa, K. (2009). Departmentally-based peer mentoring program for first year students. September 2009 FYA Essay for the National Resource Center for First Year Experiences and Students in Transition. Retrieved from http://listserv.sc.edu/cgibin $/$ wa?A2 $=$ ind0909C $\&$ L $=$ FYa-LIST $\& T=0 \& F=\& S=\& P=79$

Rodgers, R. F. (1990). An integration of campus ecology and student development: The Olentangy project. In D. G. Creamer \& Associates, College student development: Theory and practice for the 1900s (pp. 155-180). Alexander, VA: American College Personnel Association.

Ross-Thomas, E., \& Bryant, C. (1994). Mentoring in higher education: A descriptive case study. Education, 115(1), 70-77.

Schulz, S. F. (1995). The benefits of mentoring. In M. W. Galbraith \& N. H. Cohen (Eds.), Mentoring: New strategies and challenges (pp. 57-68). San Francisco: Jossey-Bass.

Schreiner, L., \& Juillerat, S. (1994). Student satisfaction inventory: 4-year college and university version. Iowa City, IA: USA Group Noel-Levitz.

Shea, G. F. (1997). Mentoring: How to develop successful mentor behaviors (rev. ed.). Menlo Park, California: Crisp Publications, Inc.

Sinclair, C. (2003). Mentoring online about mentoring: Possibilities and practice. Mentoring \& Tutoring: Partnerships in Learning, 11(1), 79-94. 
Single, P. B., \& Muller, C. B. (2000). Electronic mentoring: Quantifying the programmatic effort. (Journal Code RIEOCT2000). Paper presented at the annual meeting of the American Educational Research Association (New Orleans, LA, April 24-28, 2000. (ERIC Document Reproduction Service No. ED 440969).

Suskie, L. A. (1996). Questionnaire survey research: What works (2nd ed.). Tallahassee, FL: Association for Institutional Research.

Suskie, L. A. (2004). Assessing student learning: A common sense guide. San Francisco: Jossey-Bass.

Sweet Briar College (2010). Peer mentoring. Retrieved from http://www.arc.sbc.edu/mentoring.html

Terrion, J. L., \& Leonard, D. (2007). A taxonomy of the characteristics of student peer mentors in higher education: Findings from a literature review. Mentoring \& Tutoring: Partnership in Learning, 15(2), 149-164.

Terrion, J. L., Philion, R., \& Leonard, D. (2007). An evaluation of a university peermentoring training programme. International Journal of Evidence Based Coaching and Mentoring, 5(1), 42-57.

Tierney, J. P., \& Baldwin-Grossman, J. (2000). Making a difference: An impact study of Big Brothers Big Sisters. Philadelphia, PA: Public/Private Ventures.

Tinto, V. (1993). Leaving college. Rethinking the causes and cures of student attrition (2nd ed.). Chicago: The University of Chicago Press.

United States General Accounting Office (2004, June). Report to congressional requesters: Student mentoring programs. Washington, D.C.: United States General Accounting Office. 
University of Michigan (2010). University mentorship. Retrieved from http://www.onsp.umich.edu/incoming_freshmen/mentorship.html

Walker, G., \& Freedman, M. (1996). Social change one on one: The new mentoring movement. The American Prospect, 27(7), 75-82.

Weddington, G. (2006). Mentoring students for professional success. ASHA Leader, 11(15), 31-32.

Young, R. W., \& Cates, C. M. (2010). Listening, play, and social attraction in the mentoring of new teachers. Mentoring \& Tutoring: Partnership in Learning, (18)3, 215-213.

Zachary, L. (2000). The mentor's guide: Facilitating effective learning relationships. San Francisco: Jossey-Bass. 


\section{APPENDIX A}

Letter to Request Institutional Site Approval and Pilot Approval

(West Virginia University Letterhead)

(Date)

Address

Dear Provost (insert name):

My name is Karen L. Posa and I am a doctoral student in the Educational Leadership Program at West Virginia University in Morgantown, West Virginia. I am currently working on my dissertation research study entitled, A Study of Satisfaction and Perceived Learning and Development of Peer Mentors in Higher Education. Dr. Elizabeth A. Jones is my dissertation chair. The purpose of this letter is to request permission to survey Hillview State University students.

The purpose of my study is to examine both satisfaction and learning and development of peer mentors. Little research exists that examines university-based peer mentoring programs' learning and development of peer mentors. This study will contribute to the evidence that students who serve as peer mentors exhibit learning and development. This study will also provide an instrument for mentoring practitioners to measure perceived learning and development.

I plan to conduct a pilot study with 3 to 6 students during March 2011. These students will be asked to participate in an on-line survey and a brief follow-up interview. Results of the pilot study will ensure the quality of the instrument. Following the pilot study, I plan to survey all peer mentors who are assigned a protégé in Hillview State University's Peer Mentoring Program.

In order for me to conduct my study, I am required to receive approval from West Virginia University's and Hillview State University's Institutional Review Boards. A letter from you stating that you will permit the use of Hillview State University students to participate in the study is needed for Institutional Review Board (IRB) approval. Once I receive permission from both IRBs, I will begin the pilot study. After completing the pilot study, I will send each peer mentor a letter outlining the study and inviting them to participate.

Individual students' names will remain confidential and the information the researchers obtains from students will be aggregated. Their names and any other information that may identify participants and the institution will not be revealed in the reported results and will remain confidential. Student participation will be entirely voluntary and they can withdraw from the survey at any time. In addition, student participation in this study will not affect their class standing, grades, or membership in any organization, including 
the mentoring program. Please respond by (insert date) to inform me of your decision. If you have any questions, please feel free to contact me.

Sincerely,

Karen Posa

Doctoral Student

West Virginia University 


\section{APPENDIX B}

Letter from Institution Granting Permission for Pilot Study and Research

(On letterhead from case study institution)

(DATE)

Karen L. Posa

116 Fifth Street

California, PA 15419

Dear Ms. Posa

I am writing to indicate my support for your doctoral dissertation research at Hillview State University.

I understand that you will send each peer mentor an email outlining your study and inviting him or her to participate. You have agreed to emphasize to the students that their participation is voluntary and that they have the right to not respond to your survey. Student participation in your study will not affect their class standing, grades or membership in the mentoring program or any other student organizations or athletic teams. You have also agreed that you will not release students' names or any other identifying information, as their responses are to remain confidential.

Sincerely,

Geraldine M. Smith, Provost

Hillview State University 


\section{APPENDIX C}

Pilot Invitation Letter

(West Virginia University Letterhead)

(Date)

\section{Dear Participant:}

My name is Karen L. Posa and I am a doctoral student in the Educational Leadership Program at West Virginia University in Morgantown, West Virginia. I am currently working on my dissertation research study entitled, A Study of Satisfaction and Perceived Learning and Development of Peer Mentors in Higher Education. Dr. Elizabeth A. Jones is serving as the Principal Investigator of this study. This study has been approved for data collection by the Hillview State University Institutional Review Board. The purpose of this letter is to request your participation in a pilot study for this research study.

The purpose of my study is to examine both satisfaction and learning and development of peer mentors. Little research exists that examines university-based peer mentoring programs' learning and development of peer mentors. This study will contribute to the evidence that students who serve as peer mentors exhibit learning and development. This study will also provide an instrument for practitioners to measure perceived learning and development.

I plan to conduct a pilot study with 3 to 6 students during April 2011. If you accept this invitation to participate in the pilot study, you will be asked to complete an online survey and a brief follow-up interview. Results of the pilot study will ensure the quality of the instrument and the administering process. Following the pilot study, I plan to survey all peer mentors in Hillview State University's Peer Mentoring Program.

Individual participants' information and answers will remain confidential. The information I obtain from participants will be aggregated. Participants' names and any other information that may identify participants and the institution will not be revealed in the reported results and will remain confidential. Your participation will be entirely voluntary and you can withdraw from the questionnaire at any time. Please note that your participation in this study will not affect your class standing, grades, or membership in the mentoring program or any student organization or athletic team.

As part of this pilot study, you will be asked to complete an online survey that will take approximately 10 to 20 minutes of your time. By clicking on the following line (insert link), you will be agreeing to participate in this study and will be automatically directed to the survey instrument. 
If you have any questions about this research project, please feel free to contact Karen Posa at 724-938-1682 or via email at posa@calu.edu or Dr. Elizabeth Jones at 267-3413313 or via email at Elizabeth.Jones@mail.wvu.edu.

Sincerely,

Karen Posa, Doctoral Student West Virginia University 


\section{APPENDIX D}

\section{Survey Regarding Satisfaction, Learning, and Development of Peer Mentors in Higher Education}

\section{Demographic Questions}

Please answer the following demographic questions to the best of your ability:

1. How many credits have you "earned" as an undergraduate student?

0-29 total credits (freshman)

30-59 total credits (sophomore)

60-89 total credits (junior)

$90+$ total credits (senior)

2. How many years have you served as a peer mentor at Hillsview State University (HSU), including this year?

1 year

2 years

3 years or more

3. What was your status when you started Hillsview State University (HSU)?

Freshman student

Transfer student

4. How would you identify your residential status?

HSU's on-campus housing

HSU's Vulcan Village

Housing that is less than 5 miles from HSU's main campus

Housing that is more than 5 miles from HSU's main campus 
5. What is your age?

18 to 20 years
21 to 22 years
23 to 24 years
25 to 26 years
27 years or older

6. What is your current marital status?

Single, never married

_ Married

__ Separated

Divorced

Widowed

7. Do you have children?

Y Yes

No

8. Currently, do you live with your parents and commute to HSU?

_ Yes

No

9. What is your ethnic identification?

African American/Black

Asian American/Pacific Islander

Hispanic American/Latino/Chicano

Native American/Tribal Affiliation 
White/Caucasian/European American

International Student

_ Multi-Racial

Other, don't know, or prefer not to answer

10. What is your gender?

_Male

Female

11. What is your academic major?

12. What is your cumulative grade point average at HSU?

13. Were you a protégé before becoming a HSU peer mentor?

Yes

No

Learning and Development Questions

Please base your responses to the following questions on your mentoring experiences since becoming a peer mentor at Hillview State University.

\section{Since becoming a peer mentor:}

14. I understand the differences in my protégés and adapt my mentoring approach to meet each individual's strengths and weaknesses. (diversity)

Strongly agree

Somewhat agree

Neither agree nor disagree

Somewhat disagree

Strongly disagree 
15. I work collaboratively with my colleagues and peers to discuss solutions to problems. (collaboration)

_ Strongly agree

Somewhat agree

Neither agree nor disagree

Somewhat disagree

Strongly disagree

16. I meet with my protégés to help them identify personal and career goals.

(decision-making and problem-solving)

__ Strongly agree

Somewhat agree

Neither agree nor disagree

Somewhat disagree

Strongly disagree

17. I value working cooperatively in a team to achieve a common goal. (collaboration)

Strongly agree

Somewhat agree

Neither agree nor disagree

Somewhat disagree

Strongly disagree

18. I have had the opportunity to meet and work with people who are different than me. (diversity) 
Strongly agree

Somewhat agree

Neither agree nor disagree

Somewhat disagree

Strongly disagree

19. I am better able to help others in their decision-making and problem-solving processes. (decision-making and problem-solving)

Strongly agree

Somewhat agree

Neither agree nor disagree

Somewhat disagree

Strongly disagree

20. I have become a better listener. (communication skills)

Strongly agree

Somewhat agree

Neither agree nor disagree

_ Somewhat disagree

Strongly disagree

21. My overall interpersonal communication abilities have improved. (communication skills)

Strongly agree

Somewhat agree

Neither agree nor disagree 
Somewhat disagree

Strongly disagree

22. I am more confident speaking in public. (communication skills)

_ Strongly agree

Somewhat agree

Neither agree nor disagree

Somewhat disagree

Strongly disagree

23. I am more aware of how I learn and study. (reflection)

__ Strongly agree

Somewhat agree

Neither agree nor disagree

Somewhat disagree

Strongly disagree

24. I have adapted my study skills to be more academically successful. (academic success)

Strongly agree

Somewhat agree

Neither agree nor disagree

Somewhat disagree

Strongly disagree

25. I am more aware of my skills and abilities (e.g. communication skills, time management, and organizational skill, etc.). (reflection) 
_ Strongly agree

Somewhat agree

Neither agree nor disagree

Somewhat disagree

Strongly disagree

26. I am more effective in my time management and organizational skills. (academic success)

_Strongly agree

Somewhat agree

Neither agree nor disagree

Somewhat disagree

Strongly disagree

27. I believe that being a peer mentor has enhanced my college experience. (intrinsic benefit).

_ Strongly agree

Somewhat agree

Neither agree nor disagree

Somewhat disagree

_ Strongly disagree

28. I am more aware of university resources (such as the writing center, math lab, reading center, advisement center or tutoring center). (academic success)

Strongly agree

Somewhat agree 
Neither agree nor disagree

Somewhat disagree

Strongly disagree

29. I have utilized university resources (such as the writing center, math lab, reading center, advisement center or tutoring center) more often. (academic success)

_ Strongly agree

Somewhat agree

_ Neither agree nor disagree

Somewhat disagree

Strongly disagree

30. My grade point average has increased. (academic success)

Strongly agree

Somewhat agree

Neither agree nor disagree

Somewhat disagree

Strongly disagree

31. My decision-making and problem-solving skills have improved (decision-making and problem-solving)

Strongly agree

Somewhat agree

Neither agree nor disagree

Somewhat disagree

Strongly disagree 
32. I prefer working alone when making decisions and solving problems.

(collaboration)

Strongly agree

Somewhat agree

Neither agree nor disagree

Somewhat disagree

Strongly disagree

33. I more often participate in campus activities, events, and organizations. (student engagement)

_ Strongly agree

Somewhat agree

Neither agree nor disagree

Somewhat disagree

Strongly disagree

34. I am more confident in my abilities to lead others. (intrinsic benefits)

Strongly agree

Somewhat agree

Neither agree nor disagree

Somewhat disagree

Strongly disagree

35. I have served in at least one leadership position in a student organization. (leadership involvement)

Strongly agree 
Somewhat agree

Neither agree nor disagree

Somewhat disagree

Strongly disagree

36. I have increased my participation in leadership development opportunities (such as leadership courses and/or workshops). (leadership involvement)

Strongly agree

_ Somewhat agree

Neither agree nor disagree

_. Somewhat disagree

Strongly disagree

37. I believe my self-confidence has increased. (intrinsic benefits)

Strongly agree

Somewhat agree

_ Neither agree nor disagree

_ Somewhat disagree

Strongly disagree

38. I am more confident in my abilities to solve problems. (intrinsic benefits)

Strongly agree

Somewhat agree

Neither agree nor disagree

Somewhat disagree

Strongly disagree 
39. I know more students in my major. (student engagement)

Strongly agree

Somewhat agree

_ Neither agree nor disagree

Somewhat disagree

Strongly disagree

40. I am more comfortable interacting with professors. (student engagement)

_. Strongly agree

Somewhat agree

Neither agree nor disagree

Somewhat disagree

Strongly disagree

41. I am more comfortable asking questions in class. (student engagement)

Strongly agree

Somewhat agree

Neither agree nor disagree

Somewhat disagree

Strongly disagree

42. I feel that my involvement in the peer mentoring program has had NO effect on my learning and development. (intrinsic benefit)

Strongly agree

Somewhat agree

Neither agree nor disagree 
Somewhat disagree

Strongly disagree

\section{Satisfaction}

Please respond to the following questions on your satisfaction of mentoring experiences since becoming a peer mentor at Hillview State University.

43. The peer mentor training program sufficiently prepared me to fulfill the role of peer mentor. (mentoring experience)

_ Strongly agree

Somewhat agree

Neither agree nor disagree

Somewhat disagree

_ Strongly disagree

44. The Mentoring Staff is friendly and approachable. (mentoring program staff) Strongly agree

Somewhat agree

Neither agree nor disagree

Somewhat disagree

Strongly disagree

45. I am satisfied with the weekly information provided to me by the Mentoring Staff. (mentoring program staff)

\section{Strongly agree}

Somewhat agree

Neither agree nor disagree 
Somewhat disagree

Strongly disagree

46. I am satisfied with the protégés with whom I have been matched. (mentoring experience)

Strongly agree

Somewhat agree

Neither agree nor disagree

Somewhat disagree

Strongly disagree

47. I believe the Mentoring Staff is helpful. (mentoring program staff)

Strongly agree

Somewhat agree

Neither agree nor disagree

Somewhat disagree

Strongly disagree

48. The Mentoring Staff responds to my concerns in a timely manner. (mentoring program staff)

Strongly agree

Somewhat agree

Neither agree nor disagree

Somewhat disagree

Strongly disagree 
49. I believe the amount of time required to serve as a peer mentor is appropriate. (mentoring experience)

Strongly agree

Somewhat agree

Neither agree nor disagree

Somewhat disagree

Strongly disagree

50. I am satisfied with my experience as a peer mentor. (mentoring experience)

Strongly agree

Somewhat agree

Neither agree nor disagree

Somewhat disagree

Strongly disagree 


\section{APPENDIX E}

Interview Script for Pilot Study Participants

In response to the Survey Regarding Satisfaction, Learning, and Development of Peer Mentors in Higher Education

Thank you for agreeing to talk with me as a follow up to your participation in the pilot study on the research study entitled, A Study of Satisfaction and Perceived Learning and Development of Peer Mentors in Higher Education. I anticipate this interview will last about 15 to 30 minutes, and appreciate any information you can provide. The interview is important for the success of this study. The results of the pilot study will ensure the quality of the instrument and the administering process. Your name and responses to the following questions will remain confidential.

1) Approximately how long did it take for you to complete the survey?

2) Did you have any difficulties entering and completing the survey? Please explain.

3) Do you have recommendations on how to make the survey easier to complete? Please explain.

4) Were the items clear and easy to understand? Please explain.

5) Do you have recommendations on how to improve the items? Please explain.

6) If a random drawing were held for a prize for participants who complete the survey, what prize would you recommend within the price range of \$20 to \$200? 


\title{
APPENDIX F
}

\author{
Student Participant Invitation Letter
}

(West Virginia University Letterhead)

(Date)

\section{Dear Peer Mentors:}

This letter is a request for you to take part in a research project to examine both satisfaction and learning and development of peer mentors. This project is being conducted by Karen Posa, M.A., from the University-Wide Mentoring Program at Hillview State University for a Doctoral degree in Educational Leadership Studies. Dr. Elizabeth A. Jones is serving as the Principal Investigator of this study. This study has the approval of Provost Geraldine M. Smith, Provost of Hillview State University. Your participation in this project is greatly appreciated.

Your involvement in this study will remain as confidential as legally possible. The information that will be obtained from students will be reported in the aggregate. Your name and any other identifiable information will not be released in the reported results. All responses will remain confidential. You must be 18 years or older to participate, and your participation is entirely voluntary. In addition, you can skip questions or exit the questionnaire at any time. Please note that your participation in this study will not affect your class standing, grades, or membership in the mentoring program or any student organization or athletic team. West Virginia University's Institutional Review Board acknowledgement of this project is on file. This study has been approved for data collection by the Hillview State University Institutional Review Board.

Please note that there are no known risks or expected risks for participating in this study. There are no known direct benefits for participating in the study; however, the knowledge gained from this study may benefit the design of peer mentoring programs and may also benefit future research efforts.

By completing the survey, you will be eligible to enter into a drawing for a $\$ 20$ gift card. Ten gift cards from retailers, such as Wal-Mart, Kwik Fill, and the University Book Store will be raffled. At the end of the study, you will be directed to a site to enter your email address for the drawing. Winners of the drawing will be contacted by email. Your email address will not be connected to your survey responses and will be discarded once the drawings have been completed.

As part of this study, you will be asked to complete an online survey that will take approximately 10 to 15 minutes of your time. By clicking on the following line (insert link), you will be agreeing to participate in this study and will be automatically directed to the survey instrument. 
I hope that you will participate in this study. If you have any questions about this research project, please feel free to contact Karen Posa at 724-938-1682 or via email at posa@calu.edu or Dr. Elizabeth Jones at 267-341-3313 or via email at Elizabeth.Jones@mail.wvu.edu.

Sincerely,

Karen Posa

Doctoral Student

West Virginia University 


\title{
APPENDIX G
}

\author{
Cover Letter for SurveyMonkey ${ }^{T M}$
}

(Date)

\section{Dear Peer Mentor:}

Hello, my name is Karen Posa and I am a doctoral student at West Virginia University, majoring in higher educational leadership. Thank you for your participation in my dissertation study which examines both satisfaction and learning and development of peer mentors. Through the survey of students like you, I hope to contribute to the evidence that students who serve as peer mentors exhibit growth in learning and development. This study will also provide an instrument for mentoring practitioners to measure perceived learning and development. Dr. Elizabeth A. Jones is serving as the Principal Investigator of this study. This study has the approval of Provost Geraldine M. Smith, of Hillview State University.

Your involvement in this study will remain as confidential as legally possible. The information that will be obtained from students will be reported in the aggregate. Your name and any other identifiable information will not be released in the reported results. All responses will remain confidential. You must be 18 years or older to participate, and your participation is entirely voluntary. In addition, you can skip questions or exit the questionnaire at any time. Please note that your participation in this study will not affect your class standing, grades, or membership in the mentoring program or any student organization or athletic team. The West Virginia University Institutional Review Board's acknowledgement of this project is on file. This study has been approved for data collection by the Hillview State University Institutional Review Board.

Please note that there are no known risks or expected risks for participating in this study. There are no known direct benefits for participating in the study; however, the knowledge gained from this study may benefit the design of peer mentoring programs and may also benefit future research efforts.

By completing the survey, you will be eligible to enter into a drawing for a $\$ 20$ gift card. Ten gift cards from retailers, such as WalMart, gas cards, and HSU book store will be raffled. At the end of the study, you will be directed to enter your email address for the drawing. Winners of the drawing will be contacted by email. Your email address will be removed from your survey responses and will be discarded once the drawings have been completed. 
The online survey will take approximately 10 to 15 minutes of your time. If you have any questions about this research project, please feel free to contact Karen Posa at 724938-1682 or via email at posa@calu.edu or Dr. Elizabeth Jones at 267-341-3313 or via email at Elizabeth.Jones@mail.wvu.edu.

Sincerely,

Karen Posa

Doctoral Student

West Virginia University 